\title{
Chemogenetic Activation of Excitatory Neurons Alters Hippocampal Neurotransmission in a Dose- Dependent Manner
}

\author{
Sthitapranjya Pati, ${ }^{1}$ Sonali S. Salvi, ${ }^{1}$ Mamata Kallianpur, ${ }^{2}{ }^{\circ}$ Bhupesh Vaidya, ${ }^{3}$ Antara Banerjee, ${ }^{1}$ Sudipta \\ Maiti, ${ }^{2}$ James P. Clement, ${ }^{3 *}$ and Vidita A. Vaidya ${ }^{1^{*}}$
}

https://doi.org/10.1523/ENEURO.0124-19.2019

${ }^{1}$ Department of Biological Sciences, Tata Institute of Fundamental Research, Mumbai 400005, India, ${ }^{2}$ Department of Chemical Sciences, Tata Institute of Fundamental Research, Mumbai 400005, India, and ${ }^{3}$ Neuroscience Unit, Jawaharlal Nehru Centre for Advanced Scientific Research, Bangalore 560064, India

\begin{abstract}
Designer receptors exclusively activated by designer drugs (DREADD)-based chemogenetic tools are extensively used to manipulate neuronal activity in a cell type-specific manner. Whole-cell patch-clamp recordings indicate membrane depolarization, coupled with increased neuronal firing rate, following administration of the DREADD ligand, clozapine-N-oxide (CNO) to activate the Gq-coupled DREADD, hM3Dq. Although hM3Dq has been used to enhance neuronal firing in order to manipulate diverse behaviors, often within 30 min to $1 \mathrm{~h}$ after CNO administration, the physiological effects on excitatory neurotransmission remain poorly understood. We investigated the influence of CNO-mediated hM3Dq DREADD activation on distinct aspects of hippocampal excitatory neurotransmission at the Schaffer collateral-CA1 synapse in hippocampal slices derived from mice expressing $\mathrm{hM} 3 \mathrm{Dq}$ in $\mathrm{Ca}^{2+} /$ calmodulin-dependent protein kinase $\alpha(\mathrm{CamKIll} \alpha)$-positive excitatory neurons. Our results indicate a clear dose-dependent effect on field EPSP (fEPSP) slope, with no change noted at the lower dose of CNO $(1 \mu \mathrm{M})$ and a significant, long-term decline in fEPSP slope observed at higher doses $(5-20 \mu \mathrm{M})$. Further, we noted a robust $\theta$ burst stimulus (TBS) induced long-term potentiation (LTP) in the presence of the lower CNO (1 $\mu \mathrm{M})$ dose, which was significantly attenuated at the higher CNO $(20 \mu \mathrm{M})$ dose. Whole-cell patch-clamp recording revealed both complex dose-dependent regulation of excitability, and spontaneous and evoked activity of CA1 pyramidal neurons in response to hM3Dq activation across CNO concentrations. Our data indicate that CNOmediated activation of the hM3Dq DREADD results in dose-dependent regulation of excitatory hippocampal neurotransmission and highlight the importance of careful interpretation of behavioral experiments involving chemogenetic manipulation.
\end{abstract}

Key words: CA1; chemogenetic; CNO; DREADDs; hM3Dq; pharmacogenetic

\section{Significance Statement}

Designer receptors exclusively activated by designer drugs (DREADD) are tools to manipulate neuronal activity in specific circuits within the nervous system. Although these tools are routinely used to decipher the neuronal circuits responsible for a wide range of behaviors, effects of DREADD-mediated neuronal activation on excitatory neurotransmission remain poorly understood. In this study, we demonstrate using local field and whole-cell patch-clamp recordings, the complex dose-dependent effects of clozapine- $\mathrm{N}$ oxide (CNO)-mediated activation of excitatory DREADD hM3Dq in hippocampal excitatory neurons on distinct aspects of neurotransmission. Our results underscore the importance of careful interpretation in the use of DREADD-mediated activation of neuronal circuits. 


\section{Introduction}

Spatiotemporal control and manipulation of neuronal activity is an essential tool to understand the causal relationship between behavior and underlying neuronal circuits. Presently, two major technologies are used to perturb neuronal function: (1) optogenetic tools which are light-activated ion channels (Britt and Bonci, 2013; Xie et al., 2013; Kim et al., 2017) and (2) chemogenetic tools which are modified G-protein-coupled receptors (GPCRs) that can be activated by a pharmacologically inert ligand clozapine-N-oxide (CNO; Pei et al., 2008; Nichols and Roth, 2009; Urban and Roth, 2015; Roth, 2016). While optogenetics is immensely useful for excitation/inhibition of neuronal activity in behavioral time scales ranging from milliseconds to several minutes, chemogenetic activation/ inhibition of neuronal circuits is predominantly the method of choice for more long-term perturbations ranging from a few minutes to chronic manipulation across days (Roth, 2016; Kim et al., 2017). While both optogenetic and chemogenetic tools can be combined with inducible genetics to manipulate neuronal activity in a circuit/cell typespecific manner in precise temporal windows, optogenetics is disadvantageous for chronic manipulation due to problems such as overheating of tissue and the need to implant optical fibers by invasive surgery (Britt and Bonci, 2013; Roth, 2016; Kim et al., 2017).

The designer receptors exclusively activated by designer drugs (DREADD) hM3Dq, an engineered human muscarinic receptor, is routinely used to activate neurons (Alexander et al., 2009; Roth, 2016). The hM3Dq DREADD is coupled to Gq-signaling and like other Gq-coupled receptors, application of its agonist CNO increases accumulation of inositol monophosphate and mobilizes intracellular calcium (Armbruster et al., 2007; Guettier et al., 2009; Alexander et al., 2009; Roth, 2016). CNO administration leads to depolarization of membrane potential along with increased firing rate in hippocampal CA1 pyramidal neurons (Alexander et al., 2009), raphe serotonergic neurons (Urban et al., 2016), and arcuate nucleus AgRP neurons (Krashes et al., 2011). Although hM3Dq has been used as a tool to increase neuronal activity in several circuits including those responsible for feeding (Krashes et al., 2011; Atasoy et al., 2012), locomotion

Received April 1, 2019; accepted September 30, 2019; First published October 23, 2019.

The authors declare no competing financial interests.

Author contributions: S.P., J.P.C., and V.A.V. designed research; S.P., S.S.S., M.K., B.V., and A.B. performed research; S.P., S.S.S., and B.V. analyzed data; S.P. and V.A.V. wrote the paper; S.M. contributed unpublished reagents/analytic tools.

This work was supported by a Tata Institute of Fundamental Research intramural grant (V.A.V.), a Jawaharlal Nehru Centre for Advanced Scientific Research intramural grant (J.C.L.), and the Department of Science and Technology-Science and Engineering Research Board Grant SB/YS/LS-215/2013.

*J.P.C. and V.A.V. contributed equally to this work.

Correspondence should be addressed to James P. Clement at clement@jncasr.ac.in or Vidita A. Vaidya at vvaidya@tifr.res.in.

https://doi.org/10.1523/ENEURO.0124-19.2019

Copyright (C) 2019 Pati et al.

This is an open-access article distributed under the terms of the Creative Commons Attribution 4.0 International license, which permits unrestricted use, distribution and reproduction in any medium provided that the original work is properly attributed.
(Kozorovitskiy et al., 2012), energy expenditure (Kong et al., 2012), memory (Garner et al., 2012), and social behaviors (Peñagarikano et al., 2015), detailed neurophysiological consequences of its activation still remain poorly characterized.

Many other Gq-signaling-coupled metabotropic receptors like the metabotropic glutamate receptor 1 and 5 (mGluR1/5), muscarinic acetylcholine receptor 1 and 5 (M1/5) are known to modulate neuronal cells and circuits in distinct fashion at different doses of ligand (Volk et al., 2007; Gladding et al., 2009; Kumar, 2010; Caruana et al., 2011). Although a wide range of dosage spanning from 0.5 to $200 \mu \mathrm{M}$ CNO has been used to record hM3Dqmediated electrophysiological effects in acute slices (Mahler et al., 2014; Hurni et al., 2017), possible dosedependent variation in neuronal activity has not been studied. Further, most behavioral assays are conducted from 30 min to $1 \mathrm{~h}$ after CNO administration (Roth, 2016), a timescale in which the physiologic effects of CNO remain poorly understood.

In the current study, we have investigated the effects of acute CNO-mediated activation of the hM3Dq receptor in the $\mathrm{Ca}^{2+} /$ calmodulin-dependent protein kinase $\alpha$ (CamKII $\alpha$ )-positive excitatory neurons on hippocampal neurotransmission pre and 30 min post-CNO administration. Using the Schaffer collateral pathway as the model circuit, we show that acute hM3Dq activation in excitatory neurons produces distinctly different dose-dependent effects on field currents, paired-pulse facilitation, neuronal excitability, spontaneous postsynaptic currents (sPSCs), and ionotropic glutamate receptor-mediated currents. We also observe a dose-dependent increase in intracellular calcium levels in cultured hippocampal neurons following CNO administration. Taken together, our results suggest that hM3Dq activation in hippocampal CamKIl $\alpha$-positive excitatory neurons produces clear dose-dependent effects on neurotransmission, highlighting the importance of careful interpretation of behavioral studies using chemogenetic activation.

\section{Materials and Methods}

\section{Animals}

CamKII $\alpha$-tTA transgenic mice were received as a gift from Dr. Christopher Pittenger, Department of Psychiatry, Yale School of Medicine (Mayford et al., 1996). TetOhM3Dq mice (Cat. No. 014093; Tg(tetO-CHRM3*)1Blr/J) were purchased from The Jackson Laboratory. CamKIl $\alpha$ tTA and TetO-hM3Dq bigenic mice were bred, and the genotype of double-positive animals was confirmed using PCR-based analysis. The background strain C57BI6/J was used for control experiments. Male mice were used for all experiments. All animals were maintained on a $12 / 12 \mathrm{~h}$ light/dark cycle and provided with ad libitum access to food and water. All animal procedures were performed in accordance with the Tata Institute of Fundamental Research animal care committee's regulation.

\section{Drug administration}

CNO (Tocris) was dissolved in artificial CSF (aCSF). This solution was continuously bubbled with $95 \% \mathrm{O}_{2}$ and $5 \%$ 
$\mathrm{CO}_{2}$, and was circulated through the slice chamber during drug administration.

\section{Immunofluorescence and confocal imaging}

As the TetO-hM3Dq mouse has a hemagglutinin $(\mathrm{HA})$ tag, we performed immunofluorescence staining to visualize $\mathrm{hM} 3 \mathrm{Dq}$ expression in the hippocampus and cortex. The CamKIl $\alpha$-tTA::TetO-hM3Dq double positive or genotypecontrol animals (single positive for either CamKIl $\alpha$-tTA or TetO-hM3Dq) were sacrificed by transcardial perfusion with saline $(0.9 \% \mathrm{NaCl})$ followed by $4 \%$ paraformaldehyde. Coronal brain sections $(40 \mu \mathrm{m})$ were generated using a vibrating microtome (Leica) and subjected to immunofluorescence. Following permeabilization at room temperature in PBS with $0.4 \%$ Triton X-100 (PBSTx) for 1 $\mathrm{h}$, the sections were subjected to blocking solution [1\% bovine serum albumin (Roche, 9048-49-1), 5\% normal goat serum (Thermoscientific, PI-31873) in 0.4\% PBSTx] at room temperature for $1 \mathrm{~h}$. Sections were then incubated in the primary antibody, rabbit anti HA (1:250; Rockland, 600-401-384) for $4 \mathrm{~d}$ at $4^{\circ} \mathrm{C}$ which was followed by three washes with $0.4 \%$ PBSTx of 15 min each at room temperature. This was followed by incubation with the secondary antibody, goat anti-rabbit IgG conjugated to Alexa Fluor 568 (1:500; Invitrogen, A-11079) for two and a half hours at room temperature. The sections were mounted onto slides with Vectashield Antifade Mounting Medium with DAPI (Vector, H-1200). The sections were imaged using an LSM5 exciter confocal microscope (Zeiss) using identical acquisition settings for the sections from double-positive and genotype-control animals.

\section{Primary hippocampal neuron culture}

Hippocampi were extracted from pups of CamKII $\alpha$ tTA::TetO-hM3Dq at postnatal day 0 and tail-clips were collected for genotyping. Hippocampi were dissected in HBSS-HEPES (300 mM) buffer and incubated with $0.1 \%$ trypsin-EDTA (Invitrogen) for $10 \mathrm{~min}$. Neurons were dissociated in neurobasal medium supplemented with $2 \%$ B27 supplement and $0.5 \mathrm{mM}$ L-glutamine (Invitrogen). Cells were plated on poly-D-lysine (Sigma) coated plates at a density of $10^{6}$ cells/well in neurobasal medium. Calcium imaging experiments were conducted at day in vitro (DIV)6-DIV8.

\section{Preparation of hippocampal slices}

CamKII $\alpha$-tTA::TetO-hM3Dq or C57BI/6J mice were sacrificed by cervical dislocation in accordance with the guidelines of the Jawaharlal Nehru Center for Advanced Scientific Research animal ethics committee. Following decapitation, the brain was immediately transferred to ice-cold sucrose cutting solution (189 $\mathrm{mM}$ sucrose, 10 $\mathrm{mM}$ D-glucose, $26 \mathrm{mM} \mathrm{NaHCO} 3,3 \mathrm{mM} \mathrm{KCl}, 10 \mathrm{mM}$ $\mathrm{MgSO}_{4} .7 \mathrm{H}_{2} \mathrm{O}, 1.25 \mathrm{mM} \mathrm{NaH}_{2} \mathrm{PO}_{4}$, and $0.1 \mathrm{mM} \mathrm{CaCl}_{2}$ ), which was bubbled continuously with $95 \% \mathrm{O}_{2}$ and $5 \%$ $\mathrm{CO}_{2}$. Following dissection and removal of the cerebellum in a Petri dish containing an ice-cold cutting solution, the brain was glued onto a brain holder which was placed in a buffer tray containing ice-cold cutting solution. Subsequently, $300-\mu \mathrm{m}$ horizontal sections were obtained using a vibrating microtome (Leica, VT-1200). The sections were then transferred to a Petri dish containing aCSF $(124 \mathrm{mM}$ $\mathrm{NaCl}, 3 \mathrm{mM} \mathrm{KCl}, 1 \mathrm{mM} \mathrm{MgSO}_{4} .7 \mathrm{H}_{2} \mathrm{O}, 1.25 \mathrm{mM} \mathrm{NaH}_{2} \mathrm{PO}_{4}$, $10 \mathrm{mM}$ D-glucose, $24 \mathrm{mM} \mathrm{NaHCO}_{3}$, and $2 \mathrm{mM} \mathrm{CaCl}_{2}$ ) at room temperature following which the hippocampus and the overlying cortex was gently dissected. Slices were transferred to a chamber on a nylon mesh containing aCSF bubbled with $95 \% \mathrm{O}_{2}$ and $5 \% \mathrm{CO}_{2}$ at $37^{\circ} \mathrm{C}$. It was incubated for $30 \mathrm{~min}$ to $1 \mathrm{~h}$ to ensure stable electrophysiological responses. The slices could be maintained in a healthy state for up to $8 \mathrm{~h}$ and were transferred to the recording chamber as required.

\section{Extracellular and intracellular recording rig}

The aCSF was preheated to $34^{\circ} \mathrm{C}$ using an online Peltier controlled temperature control system (ThermoClamp-1, Automate Scientific) and circulated through the slice recording chamber (Scientifica) at $1-2 \mathrm{ml} \mathrm{min}^{-1}$ using a combination of peristaltic pump (BT-3001F, longer precision pump Co. Ltd.) and gravity feed. $\mathrm{An} \mathrm{Ag} / \mathrm{AgCl}$ reference wire and a thermocouple to provide feedback to the temperature control system were submerged in the recording chamber containing aCSF. All stimulating and recording electrodes were placed in the slice $\sim 45^{\circ}$ to the vertical and were controlled using a micromanipulator (\#1U RACK; Scientifica) which allowed movement in all three axes for correct positioning on the slice. The slice and the electrodes were visualized using an upright microscope (Slicescope pro 6000 Scientifica) with specialized optics to visualize deep tissue. The recording set up was mounted on an anti-vibration table (\#63P-541; TMC) and were enclosed in a Faraday cage. The electrical noise was eliminated by grounding all electrical connections to a single ground point in the amplifier.

\section{Recording techniques \\ Recording electrodes}

Recording electrodes were pulled from borosilicate glass capillaries (\#30-0044/GC120F-10; Harvard Apparatus) using a horizontal micropipette puller (\#P97, Sutter Instruments Co.). While intracellular patch electrodes (5-7 $\mathrm{M} \Omega$ ) were filled with potassium gluconate (KGlu) internal solution (130 mM KGlu, $20 \mathrm{mM} \mathrm{KCl,} 10 \mathrm{mM}$ HEPES free acid, $0.2 \mathrm{mM}$ EGTA, $0.3 \mathrm{mM}$ GTP-Na salt, and $4 \mathrm{mM}$ ATP-Mg salt; osmolarity adjusted to $280-310 \mathrm{mOsm}$ ), electrodes used for extracellular field recording (3-5 M $\Omega$ ) were filled with aCSF. The microelectrodes were mounted on the electrode holder (Scientifica) so that the $\mathrm{Ag} / \mathrm{AgCl}$ recording wire was in contact with the pipette solution. This holder was mounted to on a headstage which was connected to the amplifier. All signals were amplified using a Multiclamp-700B (Molecular Devices).

\section{Extracellular field recording}

The measurement of field EPSP (fEPSP) was conducted from the CA1 stratum radiatum and was measured as the potential difference between the recording electrode and the bath electrode. 


\section{Whole-cell patch-clamp recording}

Whole-cell patch-clamp recording was conducted from somata of CA1 pyramidal neurons. A positive pressure was applied to the patch pipette filled with KGlu intracellular recording solution using a tube attached to the pipette holder. With the current and voltage offset to zero, the resistance of the electrode was checked by applying a test pulse and measuring current deflection according to Ohm's law. The positive pressure was released when the pipette tip touched the cell surface which was confirmed both by visualization under the microscope and a change in resistance. This was followed by application of a negative pressure through gentle suction to form a tight seal, indicated by a large increase in resistance (>1G $\mathrm{G}$ ). The slow and fast capacitance were adjusted following which the patch of the membrane was ruptured by application of a gentle negative pressure and if required a strong voltage pulse. The cells with membrane potential less than $-55 \mathrm{mV}$ and a series resistance in the range of 5-25 $\mathrm{M} \Omega$ were considered for future experiments.

\section{Stimulation protocol}

The Schaffer collateral-commissural fiber pathway was stimulated using a concentric bipolar stimulating electrode (outer diameter: $125 \mu \mathrm{m}$, inner diameter: $25-\mu \mathrm{m}$ platinum/iridium, CBARC75, FHC). For extracellular recordings, stimulus of a square-wave pulse of $20-100 \mu \mathrm{s}$ in duration and $20-200 \mu \mathrm{A}$ in amplitude was applied using an isolated direct current stimulation box (Digimeter). For all experiments, a paired-pulse stimulus was delivered at 50-ms interval per sweep with 20-s intersweep intervals and a potentiated paired-pulse was used to confirm proper placement of electrodes in Schaffer collateral. Following the acquisition of input-output (I-O) characteristic and paired-pulse ratio (PPR), a stable baseline of the fEPSP slope was established. While I-O curves were acquired at a fixed 20- to 40- $\mu$ s duration and increasing stimulus intensity from 0 to $300 \mu \mathrm{A}$, the PPR was measured at a 10-s intersweep interval with interstimulus intervals ranging from $10-1000 \mathrm{~ms}$ in a quarter-logarithmic scale. CNO $(1,5,10$, or $20 \mu \mathrm{M})$ in aCSF was bath administered, and a constant time course was acquired for $60 \mathrm{~min}$. We selected the lowest $(1 \mu \mathrm{M})$ and highest $(20$ $\mu \mathrm{M}) \mathrm{CNO}$ dosage for additional experiments. I-O response and PPR were measured before and $30 \mathrm{~min}$ following CNO administration, while a constant time course of stimulus-induced fEPSP was recorded. To observe the long-term effects of $20 \mu \mathrm{M}$ CNO treatment, we also washed slices with aCSF post 30 min of CNO administration, and performed field recording for an additional 60 min. In a separate set of slices, $\theta$ burst stimulation (TBS) was used to induce long-term potentiation (LTP) following either sham (aCSF), a low dose (1 $\mu \mathrm{M} \mathrm{CNO}$ ) or a high dose (20 $\mu \mathrm{M}$ CNO) for hM3Dq DREADD activation. For the TBS-induced LTP-protocol, 13 blocks of a four-pulse $100-\mathrm{Hz}$ stimuli were applied with an intersweep interval of $200 \mathrm{~ms}(5 \mathrm{~Hz})$.

All measurements were done before and 30 min following CNO (1 or $20 \mu \mathrm{M})$ administration, except for AMPARand NMDAR-mediated currents for which a time course was acquired across $30 \mathrm{~min}$. Intrinsic cellular properties such as resting membrane potential (RMP), input resistance $\left(R_{N}\right)$, tau, sag voltage, were calculated by a $500 \mathrm{~ms}$, -100 to $180 \mathrm{pA}$, seven-step hyperpolarizing or depolarizing current injection with an inter sweep interval of $10 \mathrm{~s}$. To confirm cell identity by observing the shape of the action potential and calculate the action potential threshold, a current of up to $2 \mathrm{nA}$ for $2 \mathrm{~ms}$ was injected. to measure spiking activity, cells were held in current-clamp mode, CA1 pyramidal cell identity was confirmed qualitatively using the shape of action potential (characterized by the presence of an after-depolarization potential), and baseline was recorded for at least $5 \mathrm{~min}$. Spiking was observed at both a low dose $(1 \mu \mathrm{M})$ and a high dose $(20$ $\mu \mathrm{M}$ ) of CNO for 2 min followed by wash in aCSF. Spontaneous currents were measured by holding the cell in voltage-clamp mode at $-70 \mathrm{mV}$. To measure evoked responses, the Schaffer collateral-commissural pathway was stimulated using a concentric bipolar stimulating electrode (outer diameter: $125 \mu \mathrm{m}$, inner diameter: $25-\mu \mathrm{m}$ platinum/iridium, CBARC75, FHC), and cells were voltage-clamped either at $-70 \mathrm{mV}$ for AMPAR-mediated currents or $+40 \mathrm{mV}$ for NMDAR-mediated currents.

\section{Calcium imaging}

To detect intracellular calcium levels following administration of CNO, we used the UV-excitable calcium-sensitive ratiometric dye Indo-1 AM, Cell-permeable (11226, Thermo Fischer Scientific). A custom-built two-photon set up with a Ti:Sapphire laser (MaiTai DeepSee, Spectra Physics) coupled to a confocal microscope (LSM 710, Carl Zeiss), as described earlier (Das et al., 2017) was used for imaging (excitation: 730-735 nm). A microscope incubator stage (Okolab) was used to maintain temperature at $37^{\circ} \mathrm{C}$ and $5 \% \mathrm{CO}_{2}$ levels in the chamber. A combination of liquid copper sulfate filter (for infrared) and 400/30-nm bandpass filter was used to detect the emission of the calcium-bound dye. Primary hippocampal neurons (DIV6DIV8) were incubated in $10 \mu \mathrm{M}$ Indo-1 AM made in $1 \times$ HBSS (14175-079, Gibco, Life Technologies) supplemented with $100 \mathrm{nM} \mathrm{CaCl}_{2}$ for 20 min at $37^{\circ} \mathrm{C}, 5 \% \mathrm{CO}_{2}$. Following three brief washes with $1 \times$ HBSS, a baseline fluorescence of $10 \mathrm{~min}$ was acquired using a $40 \times$ objective. Following this, CNO (1 or $20 \mu \mathrm{M}$ ) was bath applied, and the neurons were tracked for $30 \mathrm{~min}$, with image stacks acquired every 2 min.

\section{Data analysis}

\section{Extracellular field recording data}

All extracellular field recording data were analyzed offline using Clampfit 10.5 (Molecular Devices). The slope of the rising phase of the fEPSP was used as a measure of the size of fEPSP to eliminate the possibility of contamination with population spikes. For the I-O measurements, the fEPSP slope was calculated with increasing stimulus intensity $(0-300 \mu \mathrm{A})$. Following a paired-pulse stimulation of the Schaffer collateral pathway, a potentiation in fEPSP slope was observed. The PPR was calculated as the ratio of the fEPSP slopes following the first stimulus to the paired stimulus following interpulse intervals of $10-1000$ $\mathrm{ms}$ on a quarter-logarithmic scale. 


\section{Whole-cell voltage/current-clamp data}

All whole-cell voltage/current-clamp data were analyzed off-line using Clampfit 10.5 (Molecular Devices). The intrinsic membrane properties were measured using voltage deflection traces from 100-pA hyperpolarizing current pulse. The $R_{N}$ was calculated by applying Ohm's law, $R=$ $\mathrm{V} / \mathrm{I}$. Where $\mathrm{V}=$ stable state voltage and $\mathrm{I}=$ injected current $(100 \mathrm{pA})$. The membrane time constant $\left(\tau_{\mathrm{m}}\right)$ was obtained by fitting the voltage decay with a single exponential $\mathrm{Ae}^{-\mathrm{t} / \tau}$ and calculating the decay constant. The sag was calculated by subtracting the steady-state voltage deflection from the peak negative-going voltage. I-O curve was obtained for the number of spikes fired in response to increasing amplitude of current injection (0$180 \mathrm{pA}$ ), from distinct sets of neurons. Following this, the accommodation index was calculated as the ratio of the maximum interspike interval (including the interval from the last spike to the end of the current injection) to the first interspike interval. The action potential threshold was defined as the voltage where the rate of change of voltage with respect to time (dV/dt) exceeded 10 versus $^{-1}$. The spontaneous current amplitude and interevent intervals were calculated using an automated event detection algorithm using Mini Analysis program (Synaptosoft Inc.). An average of at least 200 events was detected from each 5-min trace before and 30 min after CNO administration and then subjected to statistical analysis.

AMPAR-mediated current was calculated as the peak amplitude of evoked current when the cell was voltageclamped at $-70 \mathrm{mV}$, and NMDAR-mediated currents were obtained as the average current $80-100 \mathrm{~ms}$ following the time of peak response when the cell was voltage-clamped at $+40 \mathrm{mV}$. The NMDAR-mediated current decay kinetics were calculated by fitting a double exponential function in decay phase of the NMDAR-mediated current and applying the results to the following equation: $\tau_{\mathrm{w}}=\left[\mathrm{I}_{\mathrm{f}} /\left(\mathrm{I}_{\mathrm{f}}+\mathrm{I}_{\mathrm{s}}\right)\right] \mathrm{x}$ $\tau_{\mathrm{f}}+\left\{\mathrm{I}_{\mathrm{s}} /\left(\mathrm{I}_{\mathrm{f}}+\mathrm{I}_{\mathrm{s}}\right)\right\} \times \tau_{\mathrm{s}}$. Where, $\tau_{\mathrm{w}}$ is the weighted tau, $\mathrm{I}_{\mathrm{f}}$ and $I_{s}$ are the amplitudes of fast and slow currents, $\tau_{\mathrm{f}}$ and $\tau_{\mathrm{s}}$ are decay constants of fast and slow currents, respectively (Rumbaugh and Vicini, 1999).

\section{Calcium imaging data}

Calcium imaging data were analyzed using ImageJ. Following a maximum intensity projection, the time-series images were corrected for any horizontal drift using scaleinvariant feature transfer (SIFT) algorithm (Lowe, 2004). A region of interest was drawn around the neurons of interest and average intensity values were calculated. Fluorescent intensities were normalized to the baseline following which statistical analysis was performed.

\section{Statistics}

Linear regression was used to analyze the time course data, while to analyze time-binned datasets, one-way ANOVA was performed followed by Bonferroni post hoc analysis (GraphPad Prism, GraphPad Software Inc.). Data are expressed as mean \pm SEM, and statistical significance was determined at $p<0.05$. The spontaneous current data were analyzed using MATLAB (MathWorks). The amplitude and interevent interval were converted to corresponding cumulative probability distributions and then subjected to Kolmogorov-Smirnov two-sample comparison. Statistical significance was set at $p<0.001$.

\section{Results}

\section{Selective expression of hM3Dq DREADD in forebrain excitatory neurons}

The selective expression of hM3Dq DREADD in CamKIll $\alpha$ positive excitatory neurons in the forebrain was achieved by generating a bigenic mouse created by crossing CamKIl $\alpha$ tTA and TetO-hM3Dq mouse lines (Fig. 1A,B). We performed immunofluorescence analysis to detect the HA-tag and thus visualized the expression of $\mathrm{hM} 3 \mathrm{Dq}$ in hippocampal subdivisions, including the CA1 (Fig. 1C) and dentate gyrus (DG; Fig. 1D) subfields, and also in the neocortex (Fig. 1E) of CamKIl $\alpha$-tTA::TetO-hM3Dq animals. Analysis in single positive mice CamKIl $\alpha$-tTA or TetO-hM3Dq mice indicated no HA-Tag immunofluorescence in the CA1, DG hippocampal subfields or the neocortex (Fig. $1 F-H)$. Further, we confirmed the ability of CNO to induce spiking activity following bath application of both $1 \mu \mathrm{M}$ (Fig. 1/,J, $n=3$ ) and $20 \mu \mathrm{M}$ CNO (Extended Data Fig. 1-1A, $B, n=3$ ).

\section{Acute chemogenetic activation of hippocampal excitatory neurons differentially regulates field transmission in Schaffer collaterals in a dose- dependent manner}

To investigate the effects of chemogenetic activation of CamKIl $\alpha$-positive excitatory neurons on hippocampal neurotransmission, we performed time-course measurements of fEPSP slope in the stratum radiatum in response to stimulation of the Schaffer collateral-commissural fiber pathway (Fig. 2A). After establishing a stable baseline, we perfused aCSF containing different dosages of CNO following which fEPSP was recorded for $60 \mathrm{~min}$. We did not find any significant change in the fEPSP slope over time at the lowest dose of CNO (1 $\mu \mathrm{M}$; Extended Data Fig. 2-1A, $n=3)$. Interestingly, we observed a decline in fEPSP slope over time with bath application of $5 \mu \mathrm{M}$ (Extended Data Fig. 2-1B, $n=3$ ), $10 \mu \mathrm{M}$ (Extended Data Fig. 2-1C, $n=4)$, and $20 \mu \mathrm{M}$ (Extended Data Fig. 2-1D, $n=4$ ) CNO. To rule out potential non-specific effects mediated by CNO, we performed the same experiment using acute hippocampal slices from the background strain, C57BI/ $6 \mathrm{~J}$. We did not note any change in fEPSP slope over time with bath application of either $1 \mu \mathrm{M}$ (Extended Data Fig. 2-1E, $n=3$ ) or $20 \mu \mathrm{M}$ (Extended Data Fig. 2-1F, $n=3$ ) CNO. For further investigation of dose-dependent effects of CNO-mediated activation of CamKIl $\alpha$-positive excitatory neurons in the hippocampus, we chose the lowest (1 $\mu \mathrm{M})$ and the highest $(20 \mu \mathrm{M})$ dose of CNO. As evident from these results, the CNO-mediated decline in $\mathrm{FEPSP}$ slope reached steady state at around 30 min after CNO administration. Therefore, we performed time-course measurements for $30 \mathrm{~min}$ in a separate cohort of animals. We observed no change in fEPSP time course with the low dose $(1 \mu \mathrm{M})$ of CNO and a significant decline in fEPSP slope over time following high dose $(20 \mu \mathrm{M})$ of CNO administration (Fig. 2B). The fEPSP slope time course was significantly lower at $20 \mu \mathrm{M}$ CNO (linear regression followed by ANCOVA, $p<0.0001, n=5$ for $1 \mu \mathrm{M}$ and $n=$ 
A

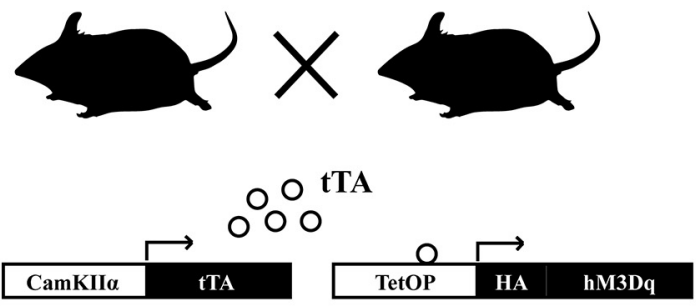

C

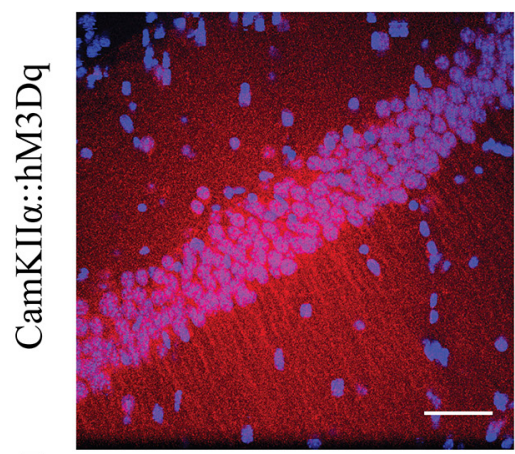

$\mathbf{F}$

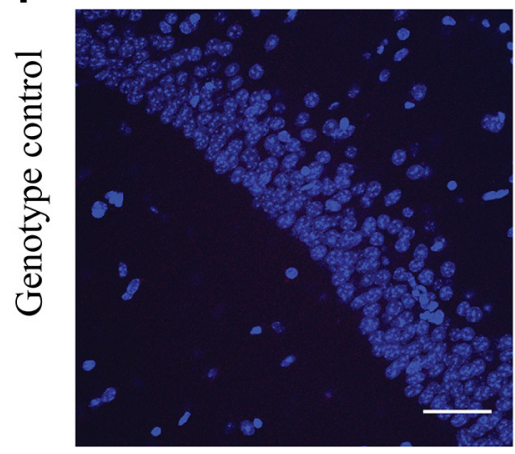

I

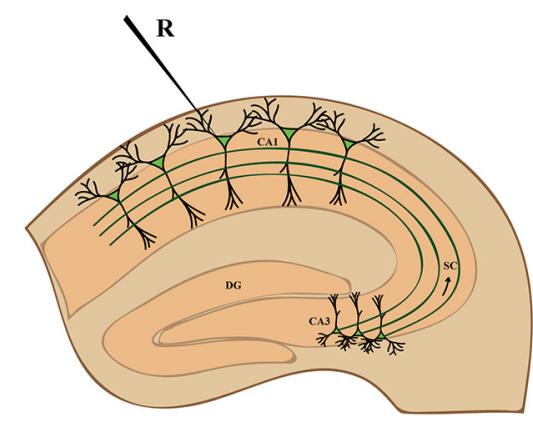

B

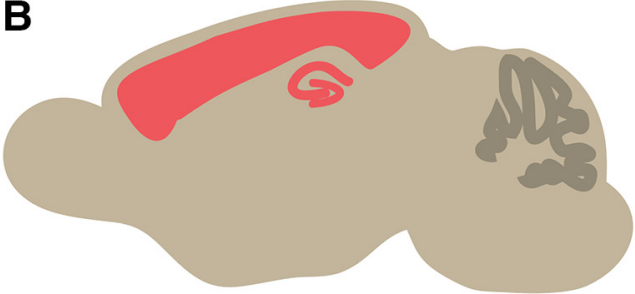

E

Cortex

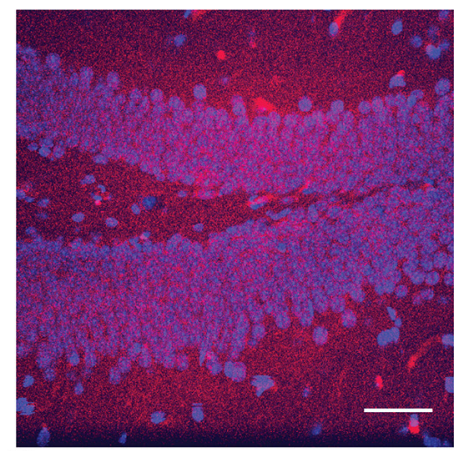

G

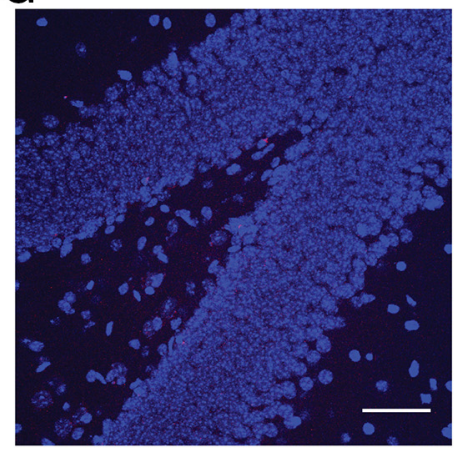

J

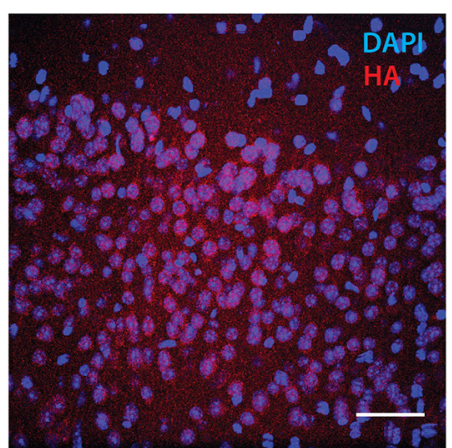

$\mathbf{H}$

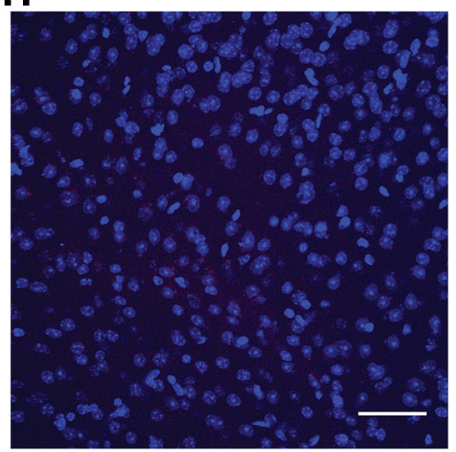

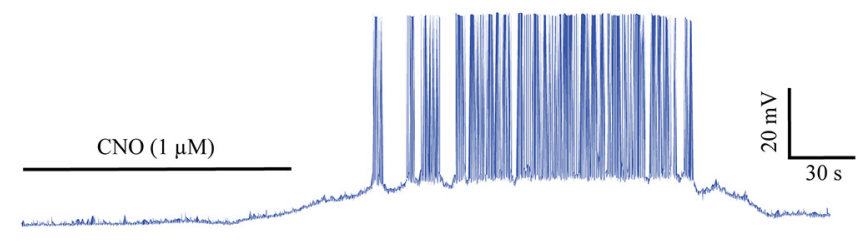

Figure 1. Selective expression of hM3Dq DREADD in forebrain excitatory neurons. $\boldsymbol{A}$, Shown is a schematic of experimental strategy. hM3Dq DREADD was selectively expressed in the CamKIl $\alpha$-positive excitatory neurons in the forebrain. tTA: tetracycline transactivator. $\boldsymbol{B}$, Shown is a schematic of the extent of expression. Representative confocal images showing expression of hM3Dq identified by fluorescent immune-staining of HA-tag in the CA1 $(\boldsymbol{C})$, DG $(\boldsymbol{D})$, and cortex $(\boldsymbol{E})$. No HA-tag immunoreactivity was observed in the genotype-control animals $(\boldsymbol{F}-\boldsymbol{H})$. Blue: DAPI; red: HA-Tag. Scale bar $=50 \mu \mathrm{m}$. $\boldsymbol{I}$, Shown is a schematic showing whole-cell patch-clamp recording from the somata of CA1 pyramidal cells. J, Bath application of CNO $(1 \mu \mathrm{M})$ resulted in robust spiking activity of CA1 pyramidal neurons. Refer to Extended Data Fig. 1-1 for spiking activity following bath application of $20 \mu \mathrm{M}$ CNO. R: recording electrode.

6 for $20 \mu \mathrm{M})$ as compared to the $1 \mu \mathrm{M}$ CNO-treated slices. to understand whether the decline in fEPSP slope caused by administration of $20 \mu \mathrm{M}$ CNO is transient or it can persist after the drug is removed, we washed out the CNO after 30 min and recorded fEPSP for an additional 60 min in a separate set of slices. The fEPSP slope further declined for $\sim 20$ min following the wash out before stabilizing, and we did not observe any recovery for at least 60 min after washout (Extended Data Fig. 2-2A, $n=7$ ). We next measured the I-O response of the pathway before CNO treatment (pre-CNO) and 30 min after CNO treatment. At low dose, we did not observe any significant 
A

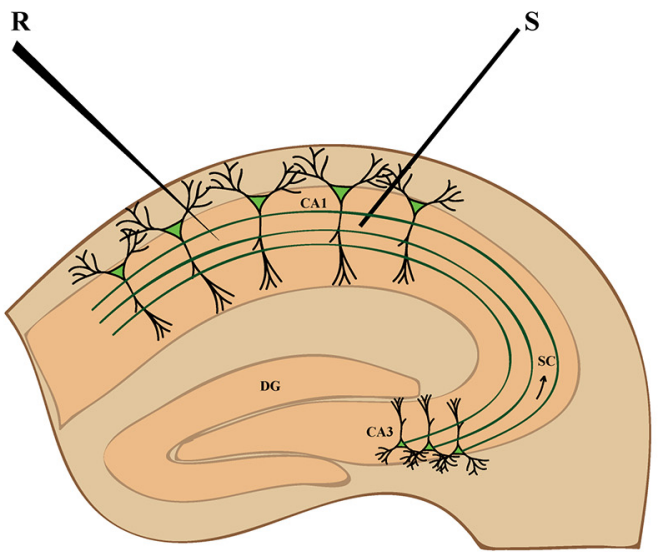

B

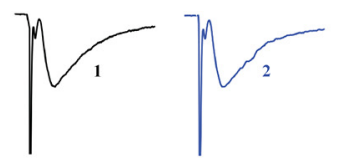

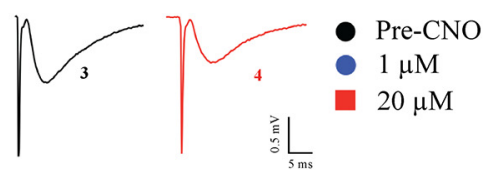

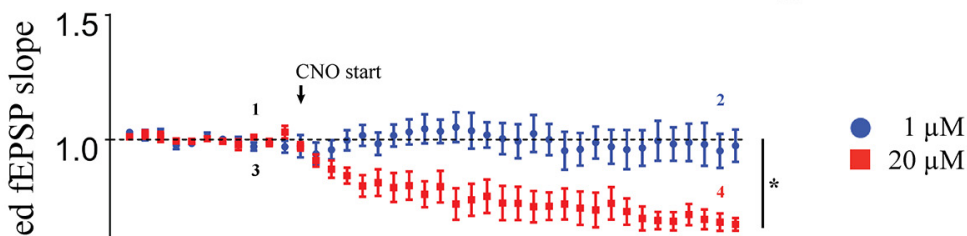

$20 \mu \mathrm{M}$
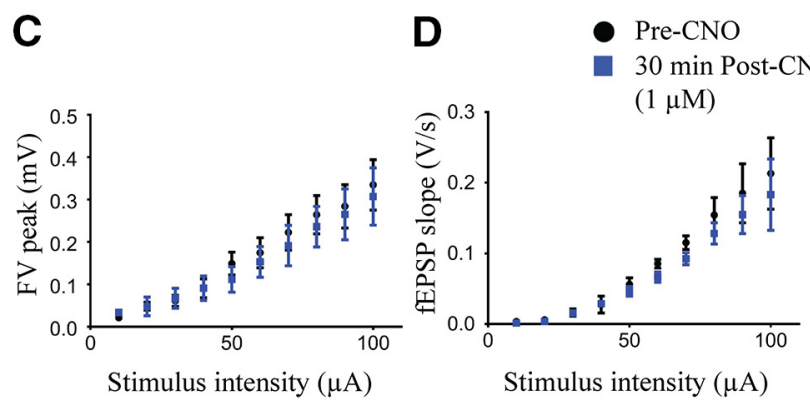

G
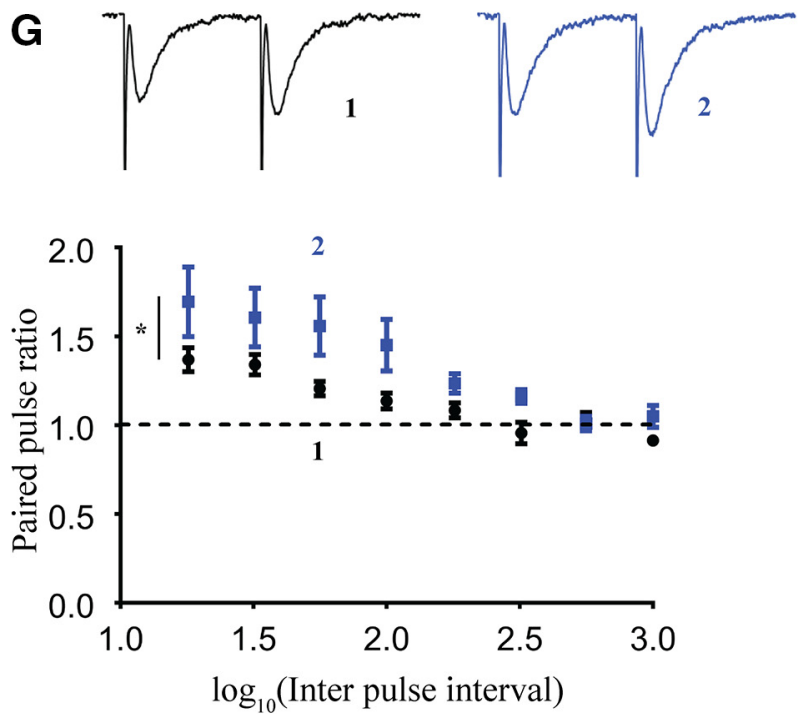

E

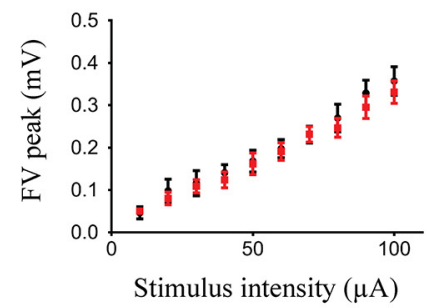

H
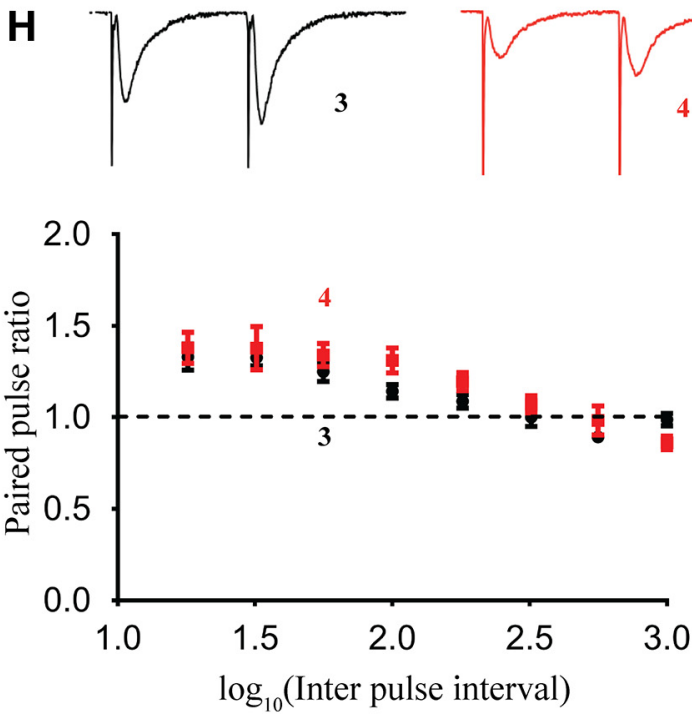

Figure 2. Acute chemogenetic activation of hippocampal excitatory neurons differentially regulates field transmission in Schaffer collaterals in a dose-dependent manner. $\boldsymbol{A}$, Shown is a schematic of placement of stimulating and recording electrode in the Schaffer collaterals. $\boldsymbol{B}$, Shown are representative fEPSP traces before (1) and $30 \mathrm{~min}$ (2) following $1 \mu \mathrm{M}$ CNO treatment and representative fEPSP traces before (3) and 30 min (4) following $20 \mu \mathrm{M}$ CNO treatment. Refer to Extended Data Fig 2-1 for genotype-controls and bath application of $1 \mu \mathrm{M}, 5 \mu \mathrm{M}, 10 \mu \mathrm{M}$, and $20 \mu \mathrm{M}$ CNO. Refer to Extended Data Fig 2-2 for fEPSP time-course following CNO-washout. Bath application of CNO did not affect fEPSP time course at $1 \mu \mathrm{M}$, whereas it led to LTD of fEPSP at $20 \mu \mathrm{M}$. Stimulus intensity: 50-80 $\mu \mathrm{A} ; 20-30 \mu \mathrm{s}$. The FV peak was not altered with increasing stimulus intensity either at $1 \mu \mathrm{M}(\boldsymbol{C})$ or $20 \mu \mathrm{M}(\boldsymbol{E})$. The fEPSP slope was not different at $1 \mu \mathrm{M}(\boldsymbol{D})$, but significantly lower in response to increasing stimulus intensity at $20 \mu \mathrm{M}(\boldsymbol{F})$. $\mathbf{G}$, Shown are representative paired-pulse-evoked fEPSP traces before (1) and $30 \mathrm{~min}$ (2) following $1 \mu \mathrm{M}$ CNO treatment. A significant potentiation of PPR was observed $(\boldsymbol{G})$ following $30 \mathrm{~min}$ of $1 \mu \mathrm{M}$ CNO bath application. $\boldsymbol{H}$, Shown are representative paired-pulseevoked fEPSP traces before (3) and 30 min (4) following $20 \mu \mathrm{M}$ CNO treatment. No significant alteration in the PPR was noted following $30 \mathrm{~min}$ of $20 \mu \mathrm{M}$ CNO bath application $(\boldsymbol{H})$. Results are expressed as the mean $\pm \mathrm{SEM} ; *<0.05$ as compared between 1 and $20 \mu \mathrm{M}$ CNO treatment (linear regression followed by ANCOVA). S: stimulating electrode; R: recording electrode. 
difference in fiber volley (FV) peak (Fig. $2 C, n=5$ ) and fEPSP slope (Fig. 2D, $n=5$ ) in response to increasing stimulus intensity. At the high dose of $\mathrm{CNO}$, we did not find any significant difference in the FV peak in response to increasing stimulus intensity (Fig. $2 E, n=5$ ). Interestingly, we found that the fEPSP slope in response to increasing stimulus intensity was lower after $30 \mathrm{~min}$ of 20 $\mu \mathrm{M}$ CNO administration (Fig. $2 F$, linear regression followed by ANCOVA, $p=0.0003, n=5$ ). Paired-pulse facilitation in the Schaffer collaterals has been shown to be mediated by presynaptic mechanisms. To assess possible presynaptic effects of $\mathrm{CNO}$ administration, we measured paired-pulse facilitation before and $30 \mathrm{~min}$ following CNO administration. Strikingly, we found a potentiated paired-pulse facilitation at 30 min following $1 \mu \mathrm{M}$ CNO administration (Fig. 2G, linear regression followed by ANCOVA, $p=0.041, n=9$ ). We did not find any significant change in PPR with increasing interpulse interval after 30 min of $20 \mu \mathrm{M}$ CNO administration (Fig. $2 H, n=10$ ) as compared to pre-CNO measurements.

The above results indicate that acute chemogenetic activation of CamKIl $\alpha$-positive excitatory neurons produces a long-term decline of fEPSP in the Schaffer collateral at a high dose $(20 \mu \mathrm{M})$ of $\mathrm{CNO}$, while no significant effect was observed on the fEPSP time course at the low dose $(1 \mu \mathrm{M})$. Further, our results from the paired-pulse facilitation experiments indicate a putative potentiation of presynaptic responses in the Schaffer collaterals following chemogenetic activation of CamKIl $\alpha$-positive excitatory neurons using a low dose $(1 \mu \mathrm{M})$ of CNO.

\section{Dose-dependent effects of acute chemogenetic hM3Dq activation on TBS-induced LTP in hippocampal slices}

To assess whether hippocampal plasticity is modulated by hM3Dq DREADD activation at the low and high dose of CNO, we induced LTP following 30 min of either 1 or 20 $\mu \mathrm{M}$ CNO. We used a weak, physiologically relevant TBS protocol. Interestingly, we observed a robust LTP of fEPSP slope in the slices pretreated with $1 \mu \mathrm{M}$ CNO for 30 min and also in sham-treated controls (Fig. $3 A, B, n=$ $5-6 /$ dose, $n=8 /$ sham). Slices pretreated with $1 \mu \mathrm{M} \mathrm{CNO}$ showed supra-threshold response during early-phase of LTP, which gradually declined and showed similar levels of potentiation as compared to sham-treated controls by 30 min after LTP induction (Fig. 3B). However, in hippocampal slices pretreated with $20 \mu \mathrm{M}$ CNO for $30 \mathrm{~min}$, TBS failed to induce LTP (Fig. $3 A, B$ ). The slopes of LTP time course following 1 and $20 \mu \mathrm{M}$ CNO were significantly different (Linear regression followed by ANCOVA, $p<$ $0.0001, n=5-6 /$ dose). As $20 \mu \mathrm{M}$ CNO administration for 30 min led to a decline in fEPSP slope, we re-analyzed the data by normalizing the fEPSP slope to $10 \mathrm{~min}$ of pre-LTP data treated as baseline which showed a significant difference between slopes of LTP time course between 1 and $20 \mu \mathrm{M}$ CNO-treated slices (Fig. $3 C$, linear regression followed by ANCOVA, $p<0.027, n=5-6 /$ dose, $n=$ $8 /$ sham). For further quantification, we binned the fEPSP slope data in 5-min intervals (5-min pre-LTP, 5-10 min after LTP, 25-30 min post-LTP, and 55-60 min after LTP).
Thirty minutes pretreatment with $1 \mu \mathrm{M} \mathrm{CNO}$, as well as aCSF sham, led to a robust induction of LTP with potentiated fEPSP slope in 5-10, 25-30, and 55-60 min postLTP time bins as compared to the pre-LTP time bin post hoc Bonferroni multiple comparisons following one-way ANOVA, $p<0.05, n=5$ for $1 \mu \mathrm{M}$ CNO, $n=8 /$ sham; Fig. $3 D, E)$. This analysis also revealed a small, but significant increase in fEPSP slopes in 5-10 and 25-30 min post-LTP time bins with no significant increase in the 55- to 60-min time bin as compared to the pre-LTP time bin following administration of $20 \mu \mathrm{M}$ CNO (post hoc Bonferroni multiple comparisons following one-way ANOVA, $p<0.05, n$ $=6$ for $20 \mu \mathrm{M}$ CNO, $n=8 /$ sham; Fig. $3 F$ ). We further compared the 5- to 10-, 25- to 30-, and 55- to 60-min post-LTP time bins between the treatment groups namely sham treatment for $30 \mathrm{~min}, 1 \mu \mathrm{M}$ CNO for $30 \mathrm{~min}$, and 20 $\mu \mathrm{M}$ CNO treatment for 30 min using one-way ANOVA. We observed a significant increase in the average fEPSP slope in the 5- to 10- and 25- to 30-min bins with $1 \mu \mathrm{M}$ CNO bath application as compared to sham-treated controls post hoc Bonferroni multiple comparisons following one-way ANOVA, $p<0.05, n=5-6 /$ dose, $n=8 /$ sham; Fig. 3G). In contrast, the average fEPSP slope following 20 $\mu \mathrm{M}$ CNO bath application in the 5- to 10-, 25- to 30-, and 55- to 60-min bins significantly reduced as compared to both sham-treated control and $1 \mu \mathrm{M}$ CNO bath application post hoc Bonferroni multiple comparisons following one-way ANOVA, $p<0.05, n=5-6 /$ dose, $n=8 /$ sham; Fig. $3 G$ ). In addition, the average fEPSP slope in the 55- to 60 -min bin with $1 \mu \mathrm{M}$ CNO bath application was significantly lower as compared to sham-treated controls post hoc Bonferroni multiple comparisons following one-way ANOVA, $p<0.05, n=5 /$ dose, $n=8 /$ sham; Fig. $3 G$ ).

These results demonstrate dose-dependent effects of CNO-mediated chemogenetic activation of CamKIl $\alpha$ positive excitatory neurons on hippocampal plasticity, with slices pretreated with low dose of CNO showing robust LTP induction, whereas TBS failed to induce LTP in slices exposed to a high dose of CNO.

\section{Acute CNO-mediated hM3Dq DREADD activation of hippocampal excitatory neurons does not alter intrinsic membrane properties}

We next performed whole-cell patch-clamp on CA1 pyramidal neurons and investigated the effects of CNO administration on intrinsic membrane properties for a duration of $30 \mathrm{~min}$. First, we generated a single action potential by injecting a step current of $2 \mathrm{nA}$ for $2 \mathrm{~ms}$ which was used to confirm CA1 pyramidal cell identity qualitatively, characterized by presence of an after-depolarization potential. We did not find any significant change in action potential threshold following 30 min of bath application of both 1 and $20 \mu \mathrm{M}$ CNO [ $n=24$ cells (pre-CNO), 6 cells $(1 \mu \mathrm{M}), 11$ cells $(20 \mu \mathrm{M}) ;$ Table 1$]$. As injection of a depolarizing pulse leads to firing of action potentials making a measurement of other membrane properties difficult, we next injected a hyperpolarizing step current of $-100 \mathrm{pA}$ for $500 \mathrm{~ms}$ and recorded the membrane voltage. We did not find any significant change in RMP, $R_{N}$, sag voltage, and accommodation index following $30 \mathrm{~min}$ of 


\section{A}
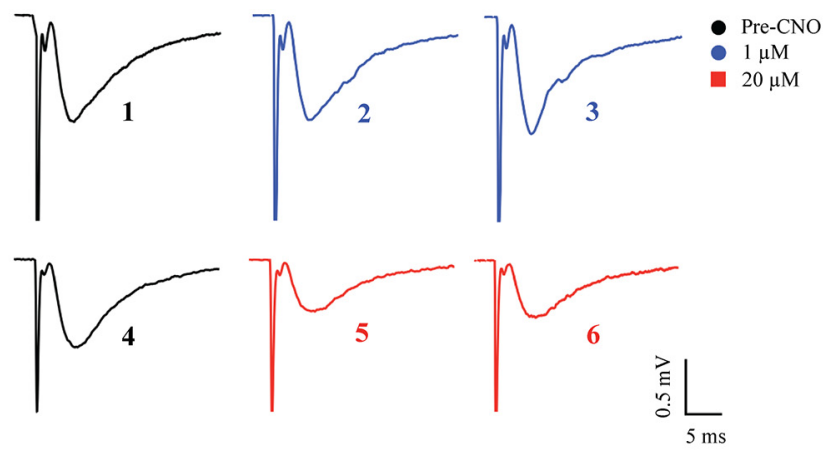

C

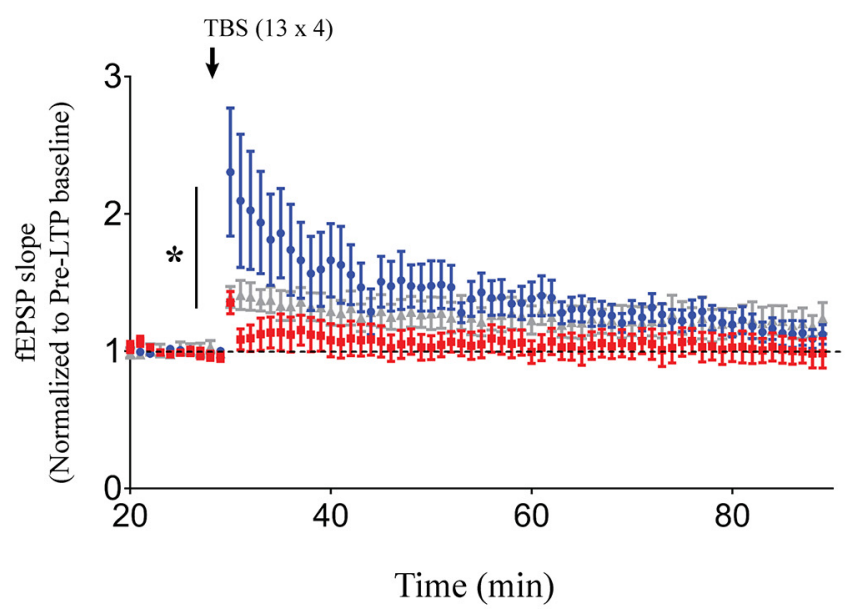

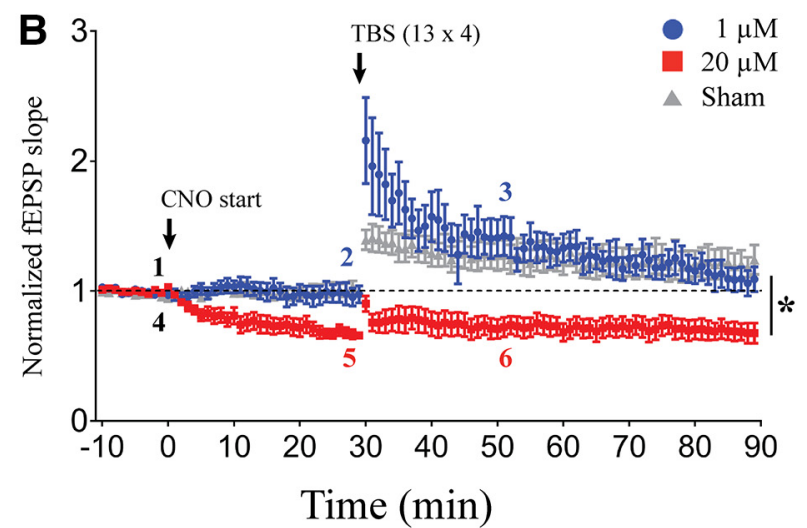

D

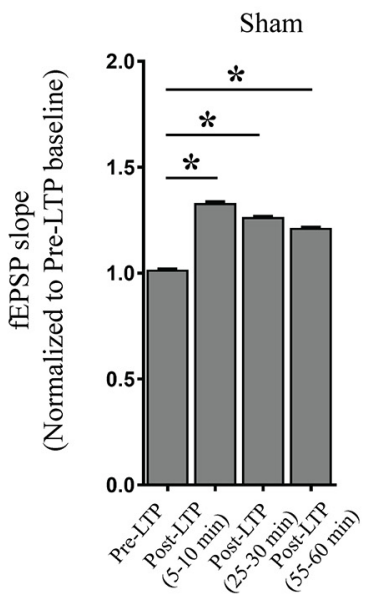

E

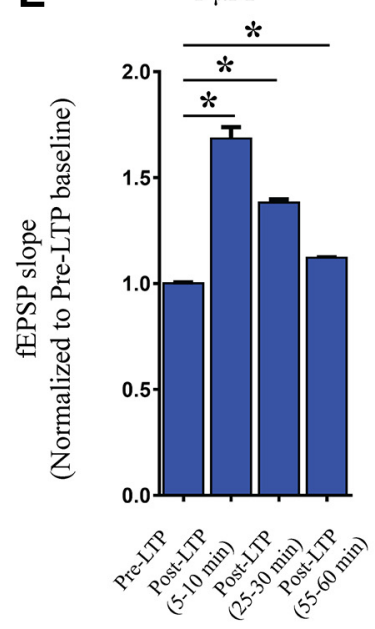

F $\quad 20 \mu \mathrm{M}$
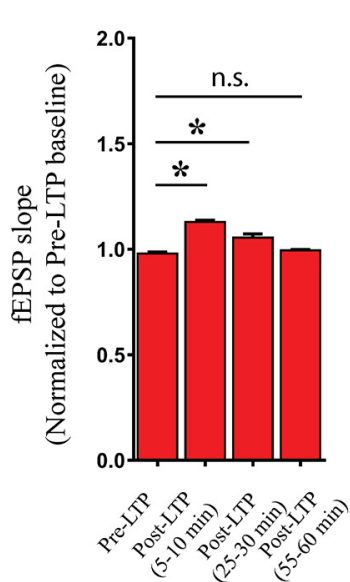

G

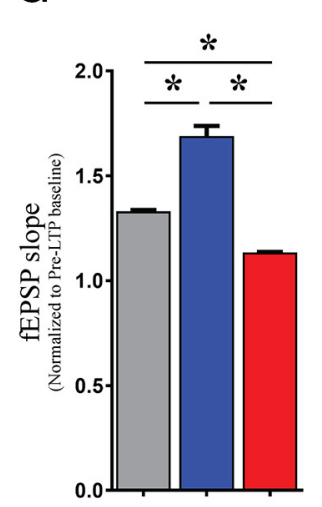

Post-LTP

(5-10 $\mathrm{min})$

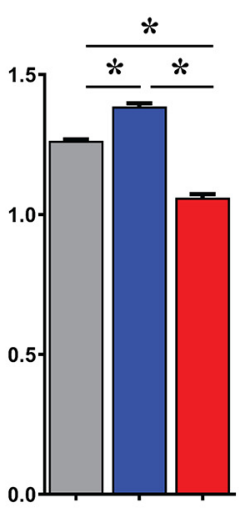

Post-LTP

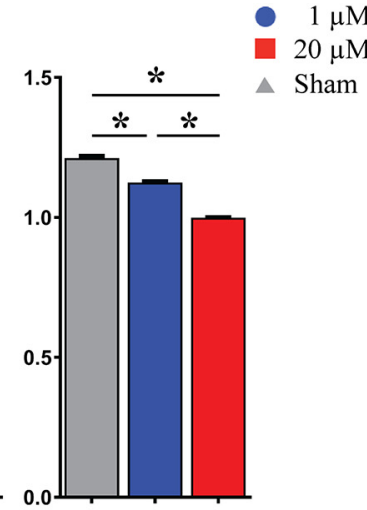

Post-LTP (55-60 min)

Figure 3. Dose-dependent effects of acute chemogenetic hM3Dq activation on TBS-induced LTP in hippocampal slices. $\boldsymbol{A}$, Shown are representative fESPS traces before, $30 \mathrm{~min}$ after CNO treatment and 20 min after LTP induction. $\boldsymbol{B}$, Slices with 30 min of $1 \mu \mathrm{M}$ CNO bath application or sham-administered control, show robust induction in LTP, with failure to induce LTP at $20 \mu$ M CNO treatment. Bath application of $1 \mu \mathrm{M}$ CNO results in a significant increase in early-phase LTP as compared to sham-treated controls. $\boldsymbol{C}$, fEPSP slope normalized to pre-LTP baseline shows robust potentiation with bath application of both sham and $1 \mu \mathrm{M}$ CNO, but not at $20 \mu \mathrm{M}$ CNO; $* p<0.05$ as compared between 1 and $20 \mu \mathrm{M}$ CNO treatment (linear regression followed by ANCOVA) for time-course analysis. The average fEPSP slope in 5-min time bins is significantly increased in 5- to 10-, 25- to 30-, and 55- to 60-min bins as compared to pre-LTP in aCSF bath (sham; $\boldsymbol{D}$ ) as well as with $1 \mu \mathrm{M}$ CNO bath application (E). The average fEPSP slope in 5 -min time bins was significantly increased 5- to 10- and 25- to 30-min bins as compared to pre-LTP with $20 \mu \mathrm{M}$ CNO bath application (F). 


\section{continued}

The average fEPSP slope was not significantly different in 55- to 60-min bin as compared to pre-LTP with $20 \mu \mathrm{M}$ CNO bath application $(\boldsymbol{F})$. Results are expressed as the mean \pm SEM; $* p<0.05$ as compared between pre-LTP and post-LTP (5-10 min), post-LTP (25-30 min), or post-LTP (55-60 min; one-way ANOVA followed by post hoc Bonferroni multiple comparison). G, The average fEPSP slope in 5-min time bins is significantly increased in 5- to 10 and 25- to 30-min bins as compared to pre-LTP with $1 \mu \mathrm{M}$ CNO bath application. The average fEPSP slope with $20 \mu \mathrm{M}$ CNO bath application in 5- to 10- and 25- to 30-min bins was significantly lower compared to both sham-treated control and $1 \mu \mathrm{M}$ CNO treatment. The average fEPSP slope in the 55- to 60-min bin was significantly lower with both 1 and $20 \mu \mathrm{M}$ CNO bath application compared to sham-treated control. Results are expressed as the mean \pm SEM; $* p<0.05$ as compared between sham, $1 \mu \mathrm{M}$, and $20 \mu \mathrm{M}$ CNO treatment for each time bin (one-way ANOVA followed by post hoc Bonferroni multiple comparison).

CNO treatment (both 1 and $20 \mu \mathrm{M}$ ) as compared to the pre-CNO baseline [ $n=24$ cells (pre-CNO), 6 cells $(1 \mu \mathrm{M})$, 11 cells $(20 \mu \mathrm{M})$; Table 1$]$.

Taken together, these data indicate that chemogenetic activation of CamKIl $\alpha$-positive excitatory neurons has no significant influence on intrinsic membrane properties of CA1 pyramidal neurons following $30 \mathrm{~min}$ of either lowdose or high-dose CNO treatment.

\section{Bidirectional dose-dependent modulation of excitability following $\mathbf{3 0} \mathrm{min}$ of $\mathrm{hM} 3 \mathrm{Dq}$ chemogenetic activation of hippocampal excitatory pyramidal neurons}

To understand possible dose-dependent effects of CNO-mediated activation of hM3Dq DREADD in CamKIl $\alpha$ positive excitatory neurons on intrinsic excitability, we injected increasing step currents and measured the number of action potentials (Fig. 4A). We found a significant increase in the number of action potentials produced in cells with 30 min of low dose $(1 \mu \mathrm{M}) \mathrm{CNO}$ bath application [linear regression followed by ANCOVA, $p=0.04$ (elevation), $n=24$ cells (pre-CNO), $n=6$ cells $(1 \mu \mathrm{M}), n=11$ cells $(20 \mu \mathrm{M})$; Fig. $4 B, C]$. Further, there was a decrease in intrinsic excitability with 30 min of pretreatment with high dose $(20 \mu \mathrm{M})$ of CNO, with a significant decline in number of action potentials generated by increasing amount of step current [linear regression followed by ANCOVA, $p=$ 0.044 (slope), $n=24$ cells (pre-CNO), $n=6$ cells $(1 \mu \mathrm{M})$, $n=11$ cells $(20 \mu \mathrm{M})$; Fig. $4 B, C]$. To understand the effects of chemogenetic hM3Dq activation on spontaneous activity of CA1 neurons, we measured SPSCs before and 30 min after activation CamKIl $\alpha$-positive excitatory neurons using the low and high doses of CNO. We saw a significant difference in SPSC amplitude with $30 \mathrm{~min}$ of low dose $(1 \mu \mathrm{M}) \mathrm{CNO}$ treatment with a decrease in cumulative probability at lower amplitudes $(<35 \mathrm{pA})$ and increased cumulative probability at higher amplitudes [KolmogorovSmirnov two-sample comparison, $p<0.001, n=13$ cells (pre-CNO), $n=7$ cells $(1 \mu \mathrm{M})$; Fig. $4 G$ ]. However, we did not observe any significant change in SPSC interevent interval $[n=13$ cells (pre-CNO), $n=7$ cells $(1 \mu \mathrm{M})$; Fig. $4 \mathrm{H}$ ] following bath application of $1 \mu \mathrm{M} \mathrm{CNO}$. Following a 30 -min treatment with high dose $(20 \mu \mathrm{M})$ of $\mathrm{CNO}$, we saw a significant decrease in both SPSC amplitude [Kolmogorov-Smirnov two-sample comparison, $p<0.001, n=13$ cells (pre-CNO), $n=7$ cells ( $20 \mu \mathrm{M})$; Fig. 4 l] and interevent interval [Kolmogorov-Smirnov two-sample comparison, $p$ $<0.001, n=13$ cells (pre-CNO), $n=7$ cells $(20 \mu \mathrm{M})$; Fig. 4J].

These data suggest that intrinsic excitability of CA1 pyramidal neurons is bidirectionally regulated following CNOmediated activation of CamKIl $\alpha$-positive excitatory neurons, with low dose CNO $(1 \mu \mathrm{M})$ increasing and high dose $(20 \mu \mathrm{M})$ of $\mathrm{CNO}$ treatment decreasing excitability, respectively. Further, the above data show dose-dependent bidirectional regulation of SPSC amplitude and frequency following CNOmediated activation CamKIl $\alpha$-positive excitatory neurons, with low-dose CNO increasing and high-dose CNO-mediated chemogenetic activation associated with decreased spontaneous activity.

\section{Dose-dependent effects of acute chemogenetic hM3Dq activation on AMPAR- and NMDAR-mediated currents}

We next sought to understand the possible cellular mechanism responsible for the decline in fEPSP and decreased synaptically-driven excitability (Fig. 2) of CA1 pyramidal cells at the higher dose of CNO treatment. As chemogenetic activation of CamKII $\alpha$-positive excitatory neurons would act by releasing glutamate and further action on glutamatergic receptors, we performed timecourse measurements of evoked AMPAR- and NMDARmediated currents from CA1 pyramidal cells for $30 \mathrm{~min}$ following administration of either low $(1 \mu \mathrm{M})$ or high dose $(20 \mu \mathrm{M})$ of CNO (Fig. 5A). AMPAR-mediated current was calculated as the peak amplitude of evoked current when the cell was voltage-clamped at $-70 \mathrm{mV}$, and NMDARmediated currents were obtained as the average current

Table 1. Acute CNO-mediated hM3Dq DREADD activation of hippocampal excitatory neurons does not alter intrinsic membrane properties

\begin{tabular}{|c|c|c|c|c|c|c|c|}
\hline & $\mathrm{RMP}(\mathrm{mV})$ & $\begin{array}{c}\text { Input } \\
\text { resistance }(\mathrm{M} \Omega)\end{array}$ & $\begin{array}{c}\mathrm{AP} \\
\text { threshold }(\mathrm{mV})\end{array}$ & $\tau(\mathrm{ms})$ & $\begin{array}{l}\text { Sag } \\
(\mathrm{mV})\end{array}$ & $\begin{array}{l}\text { Sag } \\
(\%)\end{array}$ & $\begin{array}{c}\text { Accomodation } \\
\text { index }\end{array}$ \\
\hline re- & $-61.31=$ & $194.9 \pm 10$ & $-53.61 \pm 0.59$ & $26.15 \pm 1.57$ & $-5.67 \pm 0.61$ & $39 \pm 0.61$ & $0.45 \pm 0.04$ \\
\hline ) & $-5 s$ & & 2.11 & 23. & $-4.84 \pm$ & - & \\
\hline 0 min Post-CNO $(20 \mu \mathrm{M})$ & $-62.30 \pm 1.31$ & $201.8 \pm 13.21$ & $-53.39 \pm 1.22$ & $27.05 \pm 3.03$ & $-4.71 \pm 0.72$ & $5.30 \pm 0.74$ & $0.47 \pm 0.08$ \\
\hline
\end{tabular}

AP threshold: action potential threshold; $\tau$ : membrane time constant. 

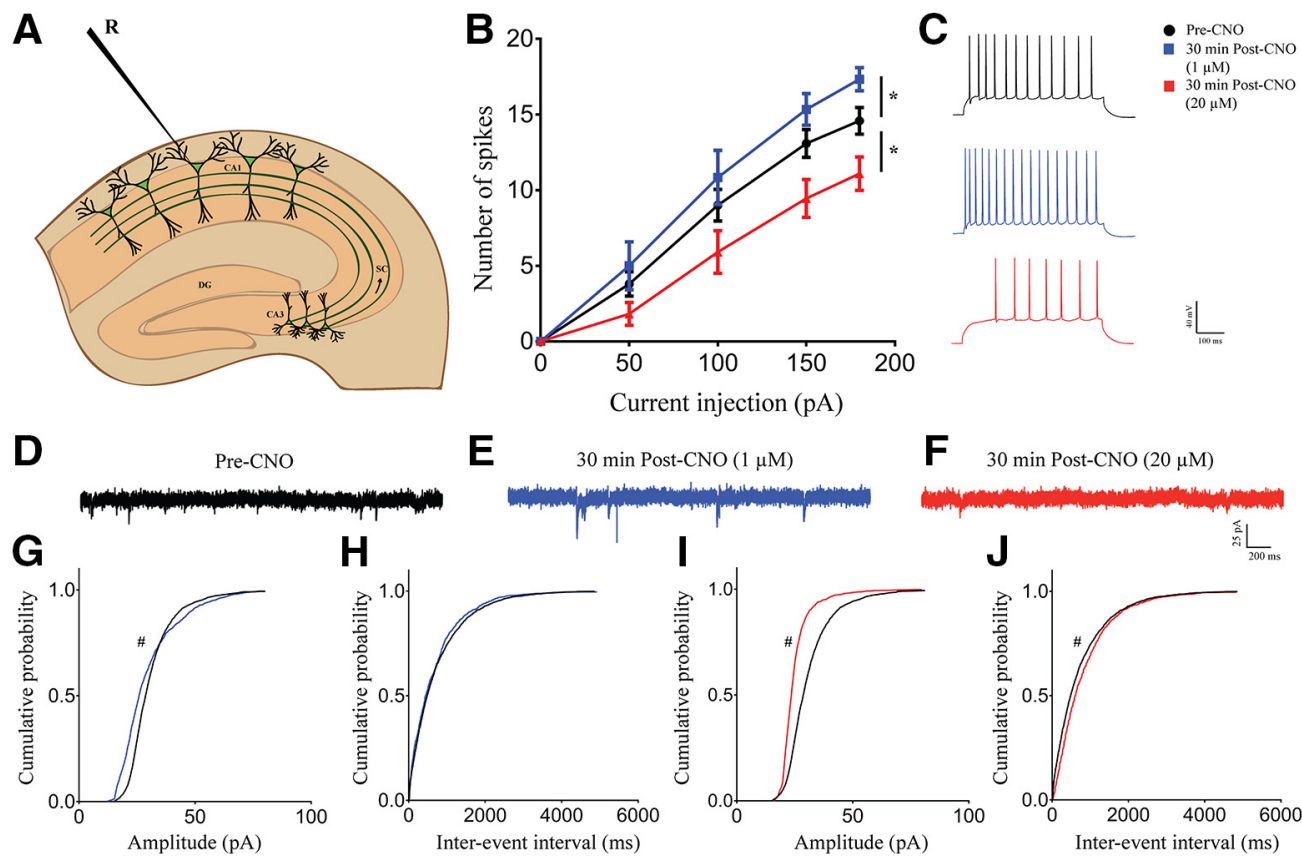

\section{E}

$30 \mathrm{~min}$ Post-CNO $(1 \mu \mathrm{M})$
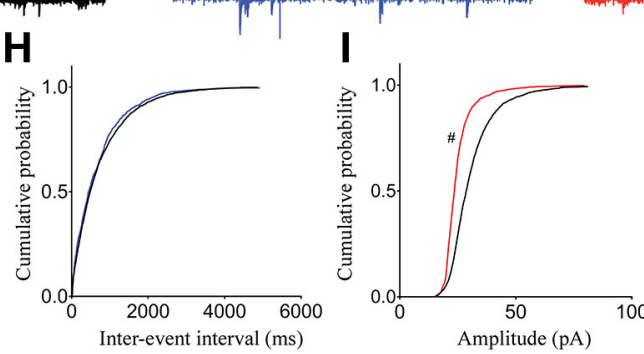

30 min Post-CNO $(20 \mu \mathrm{M})$

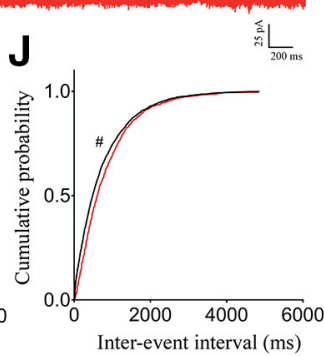

Figure 4. Bidirectional dose-dependent modulation of excitability following 30 min of hM3Dq chemogenetic activation of hippocampal excitatory pyramidal neurons. $\boldsymbol{A}$, Shown is a schematic depicting whole-cell patch-clamp recording from somata of CA1 pyramidal cells. $\boldsymbol{B}$, The number of spikes generated with increasing amount of current injection is enhanced with bath application of $1 \mu \mathrm{M}$ CNO but reduced with $20 \mu \mathrm{M}$ CNO. $\mathbf{C}$, Shown is a representative trace of action potentials from CA1 neurons before CNO treatment, after a 30-min bath application of $1 \mu \mathrm{M} \mathrm{CNO}$, and $20 \mu \mathrm{M}$ CNO. Results are expressed as the mean \pm SEM; $* p<0.05$ as compared between 1 and $20 \mu \mathrm{M}$ CNO treatment (linear regression followed by ANCOVA). Shown are representative sPSC traces before (D) and 30 min after $1 \mu \mathrm{M}(\boldsymbol{E})$ or $20 \mu \mathrm{M}(\boldsymbol{F})$ CNO treatment. Bath application of $1 \mu \mathrm{M}$ CNO for 30 min resulted in significantly altered sPSC amplitude with decreased cumulative probability at lower amplitude and increased cumulative probability at higher amplitude $(>35$ $\mathrm{pA} ; \boldsymbol{G})$, whereas no significant effect was observed on interevent interval $(\boldsymbol{H})$. Bath application of $20 \mu \mathrm{M}$ CNO for 30 min significantly decreased sPSC amplitude (I) and sPSC interevent interval ( $\boldsymbol{J}$ ). Results are expressed as cumulative probabilities; \#p < 0.001 as compared to pre-CNO-treated group (Kolmogorov-Smirnov two-sample comparison). R: recording electrode.

80-100 ms following the time of peak response when the cell was voltage-clamped at $+40 \mathrm{mV}$ (Fig. 5B). AMPARmediated-evoked current was reduced following both 1 and $20 \mu \mathrm{M} \mathrm{CNO}$ administration, but the extent of decline was greater in the $20 \mu \mathrm{M}$ CNO administered neurons as compared to $1 \mu \mathrm{M}$ CNO administered neurons [linear regression followed by ANCOVA, $p<0.0001, n=6$ cells $(1 \mu \mathrm{M}), n=5$ cells $(20 \mu \mathrm{M})$; Fig. $5 C, E$. Similarly, we saw a reduction in NMDAR-mediated currents with both 1 and $20 \mu \mathrm{M}$ CNO administration, and the magnitude of decline was higher in the $20 \mu \mathrm{M}$ CNO administered neurons as compared to $1 \mu \mathrm{M}$ CNO administered neurons [linear regression followed by ANCOVA, $p<0.0001, n=5$ cells $(1 \mu \mathrm{M}), n=6$ cells $(20 \mu \mathrm{M})$; Fig. $5 D, F$. To get a neuronal population activity, we compared average currents in 5-min bins before CNO treatment and 30 min following low and high dose of CNO treatment. We found a significant decline in both AMPAR-mediated current [one-way ANOVA followed by Bonferroni multiple comparison, $p<0.05, n=$ 11 cells (pre-CNO), $n=6$ cells $(1 \mu \mathrm{M}), n=5$ cells $(20 \mu \mathrm{M})$; Fig. 5G] and NMDAR-mediated current [one-way ANOVA followed by Bonferroni multiple comparison, $p<0.05, n=$ 11 cells (pre-CNO), $n=5$ cells $(1 \mu \mathrm{M}), n=6$ cells $(20 \mu \mathrm{M})$; Fig. $5 H]$ at both 1 and $20 \mu \mathrm{M}$ CNO as compared to pre-CNO currents. Further, post hoc Bonferroni multiple comparisons revealed that administration of $20 \mu \mathrm{M}$ CNO significantly lowered both AMPAR-mediated current (one-way ANOVA followed by Bonferroni multiple comparison, $p<0.05$ ) and NMDAR-mediated current (one-way ANOVA followed by Bonferroni multiple comparison, $p<0.05$ ) as compared to 1 $\mu \mathrm{M}$ CNO treatment. Furthermore, the AMPAR/NMDAR ratio was significantly lowered with $30 \mathrm{~min}$ of high-dose $(20 \mu \mathrm{M})$ CNO administration [one-way ANOVA followed by Bonferroni multiple comparison, $p<0.05, n=8$ cells (pre-CNO), $n$ $=8$ cells $(1 \mu \mathrm{M}), n=7$ cells $(20 \mu \mathrm{M})$; Fig. $5 /$. The time constant for NMDAR-mediated current decay was significantly lower following a 30-min treatment of both 1 and 20 $\mu \mathrm{M}$ CNO [one-way ANOVA followed by Bonferroni multiple comparison, $p<0.05, n=9$ cells (pre-CNO), $n=5$ cells ( 1 $\mu \mathrm{M}), n=6$ cells $(20 \mu \mathrm{M})$; Fig. 5 J.

Taken together, these results indicate downregulation of the ionotropic glutamate receptor-mediated currents following chemogenetic hM3Dq activation of CamKIl $\alpha$ positive excitatory neurons by $\mathrm{CNO}$ in a dose-dependent manner.

\section{Acute administration of CNO results in a dose- dependent increase in intracellular calcium levels in primary hippocampal neurons}

On CNO administration the Gq-coupled hM3Dq mobilizes intracellular calcium (Armbruster et al., 2007; Roth, 2016). As calcium and its downstream signaling are key regulators of neuronal physiology, we next sought to examine whether different doses of CNO lead to differential 
A

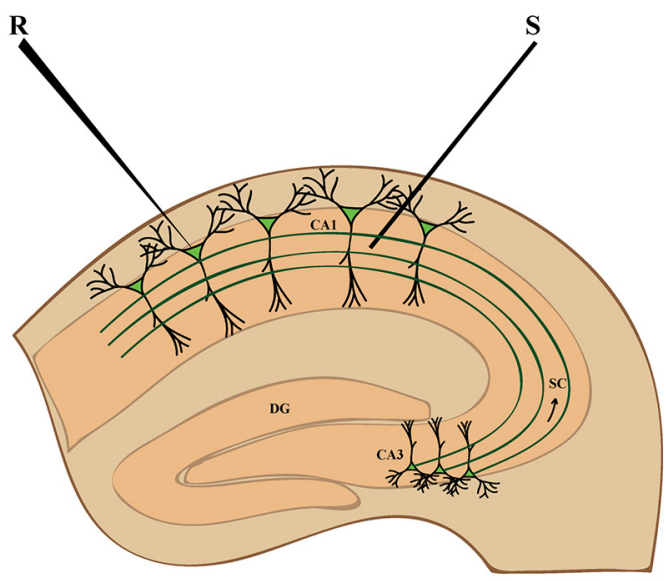

C
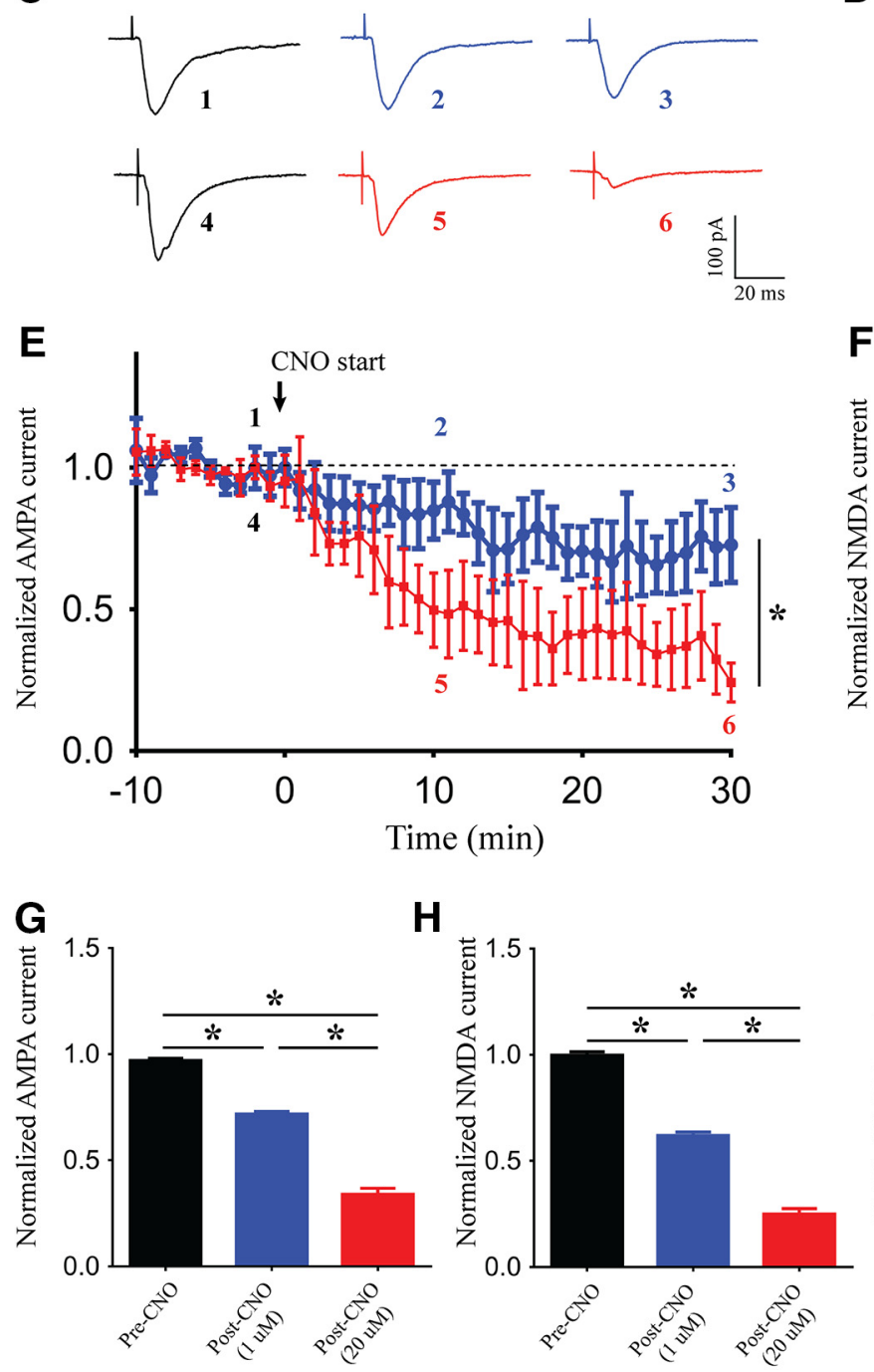

B

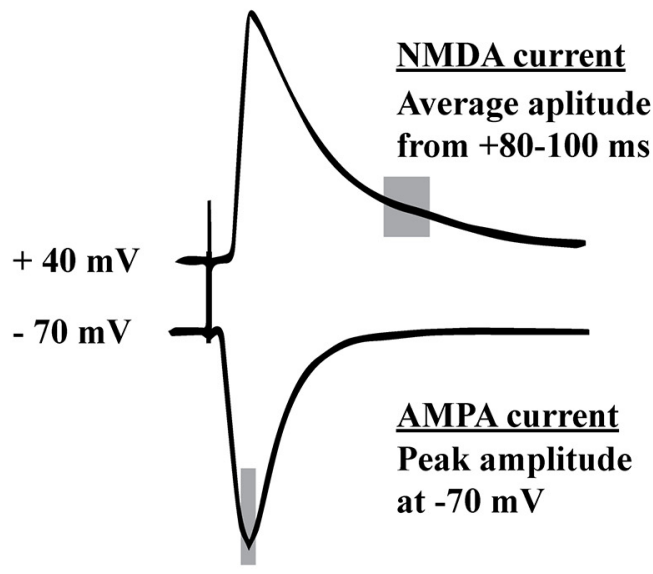

D
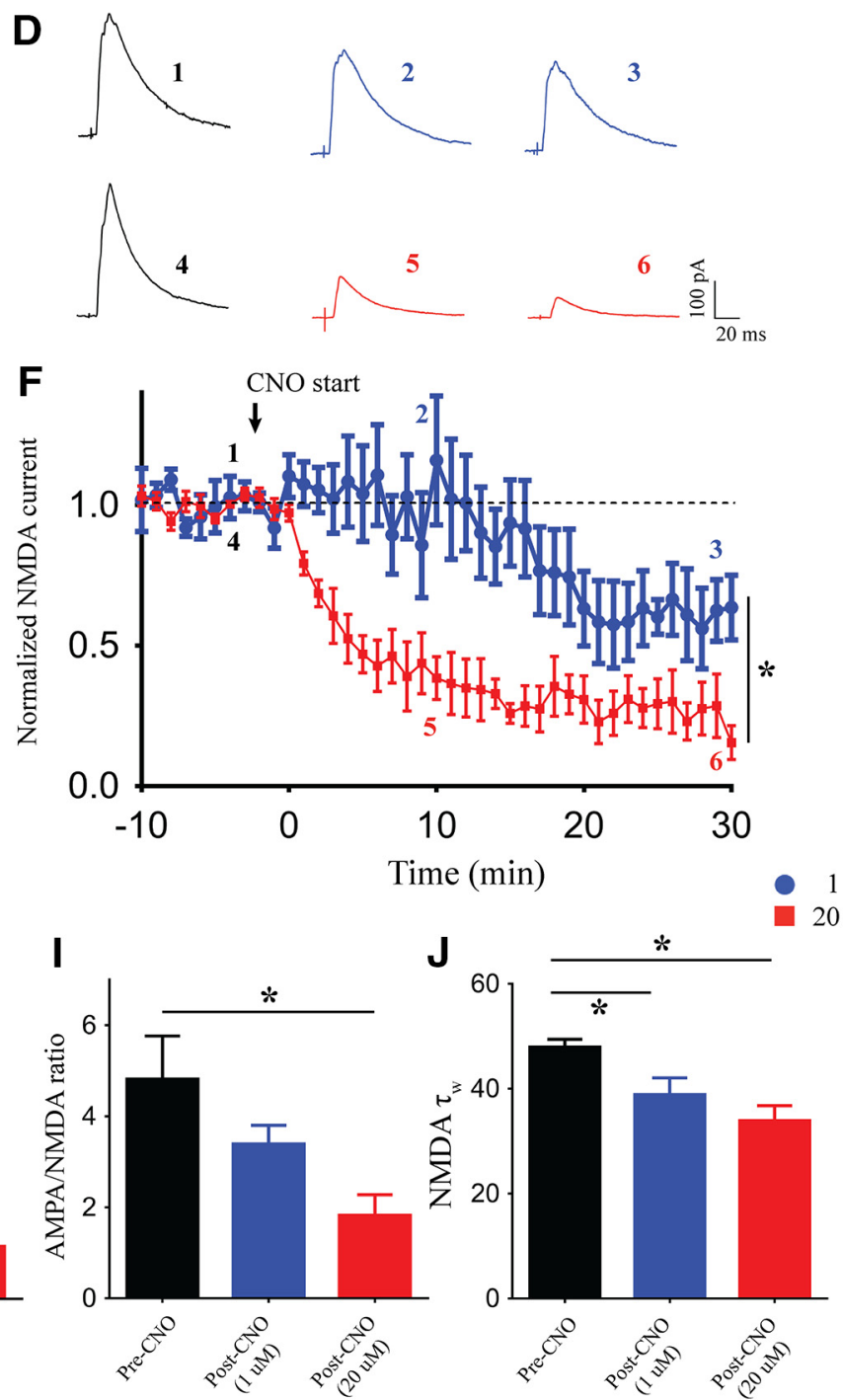

Figure 5. Dose-dependent effects of acute chemogenetic hM3Dq activation on AMPAR- and NMDAR-mediated currents. $\boldsymbol{A}$, Shown is a schematic depicting whole-cell patch-clamp recording from somata of CA1 pyramidal cells with stimulating electrodes places on the Schaffer collateral input pathway. $\boldsymbol{B}$, Shown is a schematic demonstrating the measurement of AMPAR- and NMDAR-mediated currents, respectively. $\boldsymbol{C}$, Shown are representative AMPAR-mediated-evoked PSC traces before and after 10 and 30 min of CNO bath application. Voltage clamped at $-70 \mathrm{mV}$. $\boldsymbol{D}$, Shown are representative NMDAR-mediated-evoked PSC traces before and after 10 and 30 min of CNO bath application. Voltage clamped at $+40 \mathrm{mV}$. Bath application of both 1 and $20 \mu \mathrm{M}$ CNO results in reduced AMPAR-mediated currents, with significantly lower currents at $20 \mu \mathrm{M}(\boldsymbol{E}, \boldsymbol{G})$. Bath application of both 1 and $20 \mu \mathrm{M}$ CNO results in 


\section{continued}

reduced NMDAR-mediated currents, with significantly lower currents at $20 \mu \mathrm{M}(\boldsymbol{F}, \boldsymbol{H})$. AMPAR/NMDAR ratio is significantly reduced with bath application of $20 \mu \mathrm{M}$ CNO (I). The time constant of NMDAR-mediated current decay $(\tau)$ is significantly decreased following 30 min of both 1 and $20 \mu \mathrm{M}$ CNO administration ( $\boldsymbol{J}$. Results are expressed as the mean \pm SEM; $* p<0.05$ as compared between 1 and $20 \mu \mathrm{M}$ CNO treatment (linear regression followed by ANCOVA) for time-course analysis; $* p<0.05$ as compared between pre-CNO, 1 and $20 \mu \mathrm{M}$ CNO treatment (one-way ANOVA followed by post hoc Bonferroni multiple comparison) for others. S: stimulating electrode; R: recording electrode.

intracellular calcium dynamics using a ratiometric calcium-sensitive dye Indo-1. Using two-photon calcium imaging, we measured intracellular calcium levels in primary hippocampal neurons following administration of either 1 or $20 \mu \mathrm{M}$ of CNO. We observed a significant increase in calcium levels as noted from an increase in fluorescence intensity at both $1 \mu \mathrm{M}$ (linear regression, $p<0.0001$; Fig. $6 A, B$ ) and $20 \mu \mathrm{M}$ (linear regression, $p=0.0002$; Fig. $6 A, B)$. Further, we also noted that administration of $20 \mu \mathrm{M}$ CNO exhibited different calcium dynamics from the low dose of $\mathrm{CNO}$, with a significantly faster increase in intracellular calcium levels in the first 10 min as compared to 1 $\mu \mathrm{M}$ CNO (linear regression followed by ANCOVA, $p=$ $0.012, n=5$ cells/group, from three animals; Fig. $6 B$ ). Post $10 \mathrm{~min}$, the intracellular calcium appeared to reach steady-state levels in cultured hippocampal neurons following acute CNO administration, and was not significantly different between 1 and $20 \mu \mathrm{M}$ of CNO.

Taken together, our data show a dose-dependent increase in calcium levels following acute CNO administration in cultured hippocampal neurons with $20 \mu \mathrm{M}$ CNO resulting in a significantly faster elevation in intracellular calcium levels than $1 \mu \mathrm{M}$ CNO administration.

\section{Discussion}

Our results provide novel insights into the dosedependent regulation of hippocampal neurotransmission and plasticity by CNO-mediated activation of the hM3Dq DREADD in CamKIl $\alpha$-positive excitatory neurons. We observed a significant decline in fEPSP slope in a dosedependent manner with no effect at the low dose $(1 \mu \mathrm{M})$ and the maximum decline noted at the high dose $(20 \mu \mathrm{M})$ of CNO. Further, dose-dependent effects on hippocampal plasticity were indicated by a robust induction of TBSevoked LTP in the presence of a low dose of CNO, which was not observed with the high CNO dose. In keeping with these results, the low dose of CNO potentiated PPR and increased excitability, accompanied by an intriguing regulation of the SPSC with enhanced probability for low amplitude events following $1 \mu \mathrm{M} \mathrm{CNO}$ bath application. In contrast, we observed a significant decline in excitability and SPSC at the Schaffer collateral synapses, $30 \mathrm{~min}$ following bath application of a high dose of CNO. Taken together, our findings provide novel evidence for the complex nature of modulation of hippocampal neurotransmission following hM3Dq DREADD activation by different doses of the ligand, CNO.

The hM3Dq DREADD is a chemogenetic tool widely used to activate neurons in a circuit and cell type-specific manner that provides critical spatiotemporal control of neurocircuitry, thus facilitating the establishment of causal links between specific neuronal pathways and be- havior (Roth, 2016). Application of the DREADD ligand CNO activates the canonical Gq-signaling pathway enhancing intracellular $\mathrm{Ca}^{2+}$ levels (Armbruster et al., 2007; Alexander et al., 2009), and is thought to thus increase neuronal firing. Several studies have demonstrated increased firing rate and membrane depolarization in hippocampal CA1 pyramidal neurons (Alexander et al., 2009), raphe serotonergic neurons (Urban et al., 2016), and arcuate nucleus AgRP neurons (Krashes et al., 2011; Atasoy et al., 2012) in response to CNO-mediated hM3Dq activation. However, these studies employ a wide range of CNO doses ranging from $0.5-200 \mu \mathrm{M}$, and have performed recordings predominantly for short time scales of a few minutes following CNO administration (Mahler et al., 2014; Hurni et al., 2017). Given that most behavioral paradigms with acute hM3Dq DREADD activation operate across timescales of $30 \mathrm{~min}$ to several hours using diverse CNO dose ranges, it is critical to gain insight into the impact of CNO-based hM3Dq DREADD activation on neurotransmission, incorporating both different doses and longer time durations. Here, we show that CNOmediated hM3Dq DREADD activation exerts complex, dose-dependent effects on hippocampal neurotransmission, including fEPSP slope, neuronal excitability, spontaneous and evoked activity, as well as plasticity.

Our results recapitulate aspects of prior studies examining the influence of endogenous Gq-coupled GPCR activation on hippocampal neurotransmission. Increased excitability and potentiation of an LTP phenotype are noted with the M1 muscarinic agonist, carbachol that activates Gq-signaling (Burgard and Sarvey, 1990; Bröcher et al., 1992; Natsume and Kometani, 1997). Prior evidence indicates that the mGluR1/5 agonist (R,S)-3,5dihydroxyphenylglycine (DHPG)-dependent LTP is associated with increased excitability of CA1 pyramidal neurons and requires activation of protein kinase $C$, that lies downstream to Gq-signaling (Brager and Johnston, 2007). In addition, stimulation of the Gq-coupled muscarinic AChR 1 and 5 (mAChR; M1/5) leads to facilitation of LTP and synaptic transmission in both the hippocampus and visual cortex (Burgard and Sarvey, 1990; Bröcher et al., 1992; Natsume and Kometani, 1997). It is of interest that our results with the low dose of CNO $(1 \mu \mathrm{M})$ are similar to components of the phenomena associated with activation of either the M1/5 or Group I mGluR in the hippocampus. In contrast, bath administration of both mGluR1/5 and mAChR; M1/5 agonists (Palmer et al., 1997; Cobb and Davies, 2005; Gladding et al., 2009; Kumar, 2010; Caruana et al., 2011) are also known to evoke long-term depression (LTD) at the Schaffer collateral synapses, which is similar to the effects we noted 
A
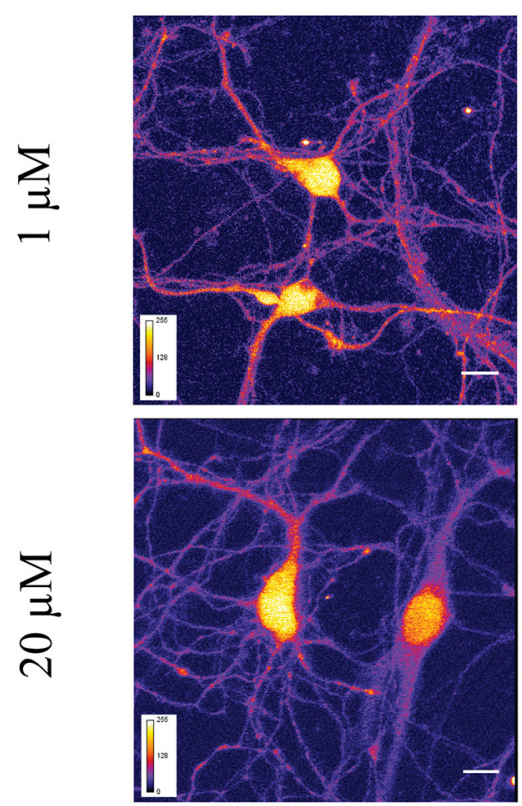

$+4 \min$
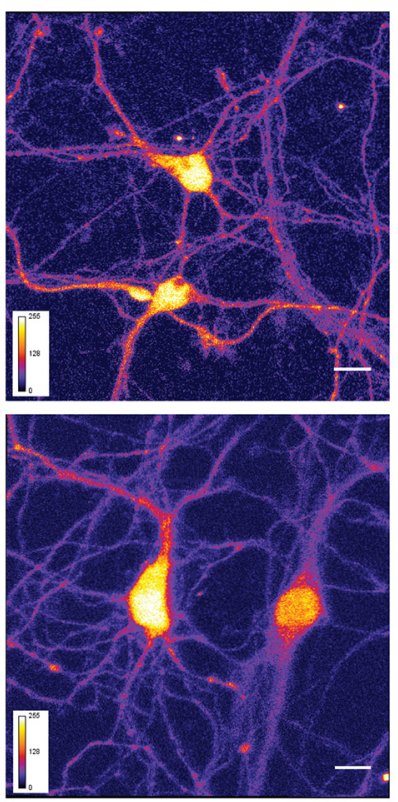

$+8 \min$
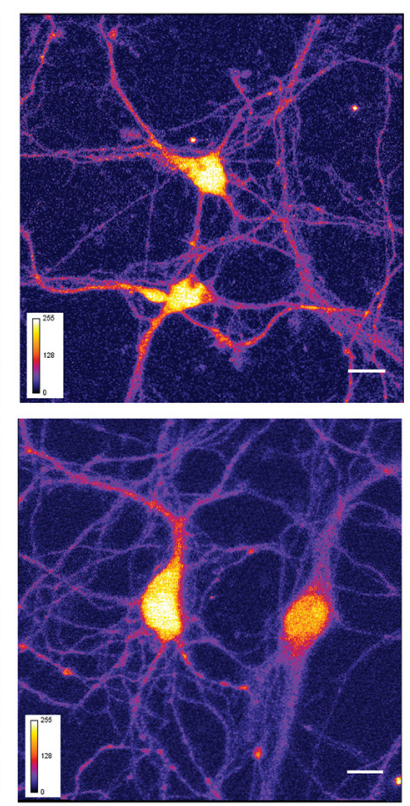

$+12 \min$
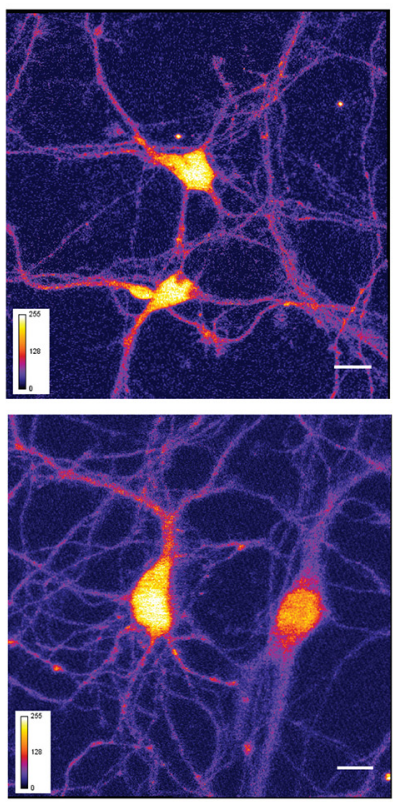

B
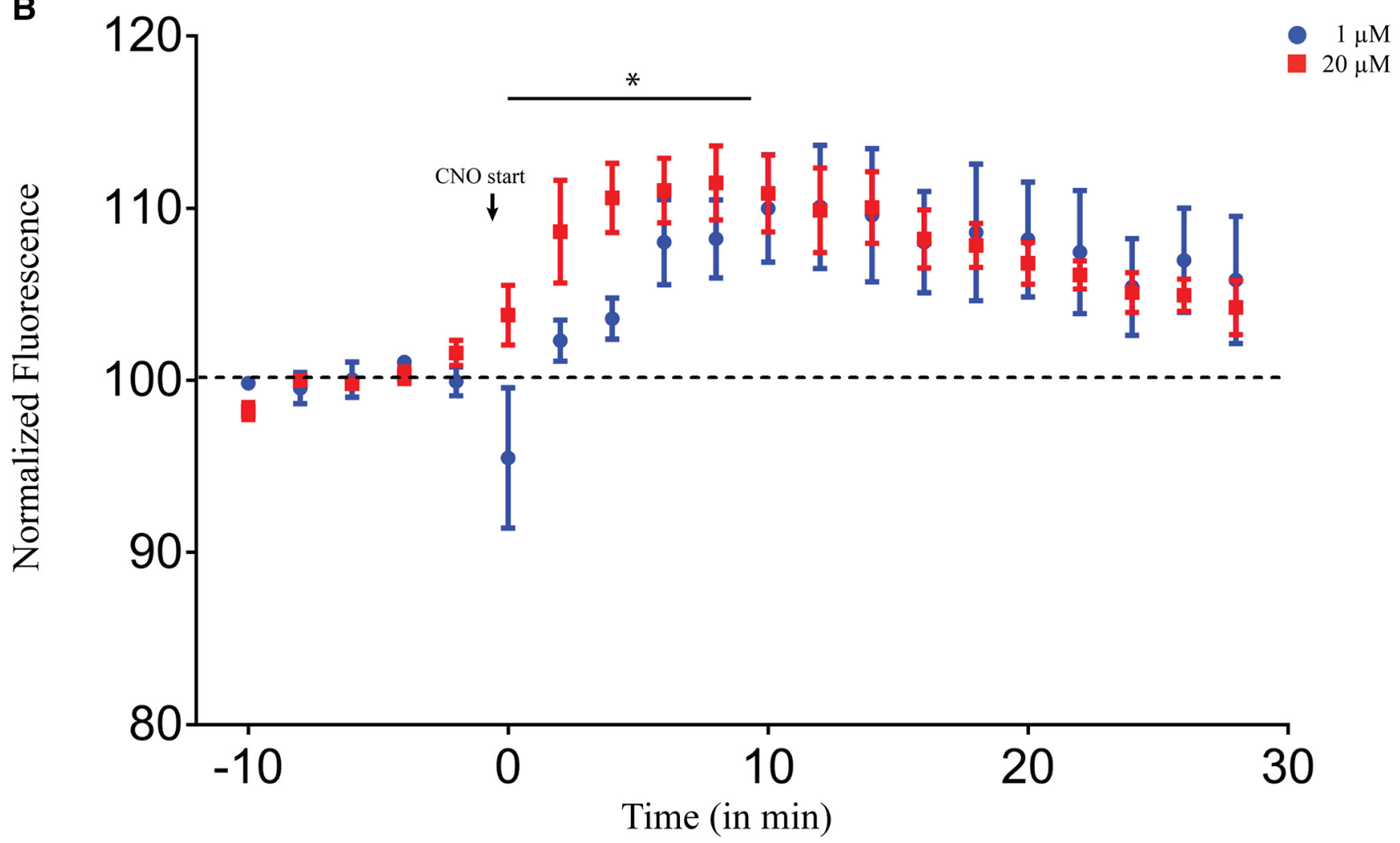

Figure 6. Acute administration of $\mathrm{CNO}$ results in a dose-dependent increase in intracellular calcium levels in primary hippocampal neurons. $\boldsymbol{A}$, Shown are representative images of primary hippocampal neurons before CNO-treatment and 4, 8, and 12 min following $1 \mu \mathrm{M}$ (top) or $20 \mu \mathrm{M}$ (bottom) CNO treatment. $\boldsymbol{B}$, Application of both 1 and $20 \mu \mathrm{M}$ CNO significantly increased intracellular calcium levels as observed by increased fluorescence intensity. Treatment with $20 \mu \mathrm{M}$ CNO resulted in a significantly faster increase in intracellular calcium levels as compared to $1 \mu \mathrm{M}$ CNO. Results are expressed as the mean $\pm \mathrm{SEM} ; * p<0.05$ as compared between 1 and $20 \mu \mathrm{M}$ CNO treatment (linear regression followed by ANCOVA). 
with the high dose of CNO $(20 \mu \mathrm{M})$ used to evoke hM3Dq DREADD activation. In addition, we did not observe the recovery of the decline in fEPSP slope even after $60 \mathrm{~min}$ of washing with aCSF, which indicates that the effect of $\mathrm{hM} 3 \mathrm{Dq}$ activation with high dose of the ligand evokes an LTD-like change, and could involve long-term changes in neuronal function. Previous reports demonstrate that bath application of broad-spectrum mGluR agonists $( \pm)-1$ aminocyclopentane-trans-1,3-dicarboxylic acid (ACPD; Schoepp et al., 1999), mGluR1/5 agonist DHPG (Schoepp et al., 1999), and mGluR5-specific agonist (R,S)-2-chloro5-hydroxyphenylglycine (CHPG; Palmer et al., 1997; Fitzjohn et al., 1999; Huber et al., 2000), also induces robust LTD in several brain regions, including the Schaffer collaterals (Bellone et al., 2008; Gladding et al., 2009). It is not possible to directly compare the doses of CNO used in our study to evoke hM3Dq DREADD activation, to agonists used in prior studies to stimulate the mGluR1/5 and mAChR. However, it is of note that hM3Dq DREADD activation at distinct doses exerts effects that recapitulate aspects of prior findings with mGluR $1 / 5$ and $\mathrm{mAChR}$ stimulation, which are known to evoke dose-dependent, differential effects on hippocampal neurotransmission, as well as divergent effects on plasticity. Our results suggest that the engineered hM3Dq DREADD may share some similarities to endogenous Gq-coupled receptor counterparts, and thus exert complex regulation on hippocampal neurotransmission via modulation of Gq-signaling.

Our data indicate that potentially both postsynaptic and presynaptic mechanisms are triggered following bath application of CNO, and these responses likely differ across doses of CNO. We observe downregulation in AMPARand NMDAR-mediated currents following both low and high dose of CNO application, which supports the possibility of postsynaptic modulation by CNO-mediated hM3Dq activation. Cross talk between Gq-coupled signaling pathways and ionotropic glutamate receptors (iGluRs) has been shown extensively (Mao et al., 2005; MacDonald et al., 2007; Gladding et al., 2009). mGluRevoked LTD is associated with downregulation of surface AMPAR (Rush et al., 2002; Huang et al., 2004; Davidkova and Carroll, 2007; Moult et al., 2008), as well as internalization of NMDA receptors from the synapse (Snyder et al., 2001). Despite the decrease in AMPAR- and NMDAR-mediated currents, we did not observe a decline in fEPSP slope following bath application of $1 \mu \mathrm{M}$ CNO. While our results do not allow us to delineate the mechanisms responsible for this phenomenon, we could speculate a possible compensatory potentiation of presynaptic responses, supported by our observation of enhanced PPR following $1 \mu \mathrm{M}$ CNO administration. Our current experiments do not allow us to completely reconcile the differential effects of CNO-mediated hM3Dq-DREADD activation on fEPSP, PPR, and AMPAR-mediated currents and are suggestive of possible complex underlying mechanisms that require future experiments.

We noted a potentiation of PPR and increased excitability following 30 min of $\mathrm{CNO}$ bath application only at the low dose. Activation of Gq-coupled receptors increases intracellular $\mathrm{Ca}^{2+}$ (Berridge, 1993; Nakamura et al., 2000; Larkum et al., 2003; Billups et al., 2006), it is possible that bath application of different doses of CNO could lead to different concentrations of intracellular $\mathrm{Ca}^{2+}$, both at the presynapse and postsynapse. Different levels and temporal kinetics of intracellular concentration of $\mathrm{Ca}^{2+}$ are capable of recruiting distinct signaling pathways (Berridge, 1998; Augustine et al., 2003; Thomas et al., 1996). With a body of literature showing coupling of intracellular $\mathrm{Ca}^{2+}$ to Gq-coupled GPCR activation (Berridge, 1993, 2009; Nakamura et al., 2000; Larkum et al., 2003; Billups et al., 2006), differential responses including iGluR currents and SPSC may arise as a consequence of differential intracellular $\mathrm{Ca}^{2+}$ dynamics. Further careful investigation is required to tease out the exact role of downstream $\mathrm{Ca}^{2+}$-mediated signaling in mediating complex regulation of neuronal physiology by hM3Dq DREADD activation.

Our data differ from the results of López et al. (2016), demonstrating enhanced LTP following bath application of CNO $(5 \mu \mathrm{M})$ in $\mathrm{C} 57 \mathrm{BI} / 6$ animals virally expressing hM3Dq in CamKIl $\alpha$-positive neurons in the CA1. The differences in results could be due to the fact that the expression of hM3Dq was driven using viral versus bigenic mouse lines, and was spatially restricted to just the CA1 versus the entire hippocampus, in addition to other differences in age of animals used. This further substantiates the argument to be careful when interpreting neuronal activation/behavioral data using chemogenetic tools. To rule out off-target effects of CNO and its metabolites, we performed fEPSP time-course measurements in hippocampal slices derived from the background C57BI/6J mice lacking the hM3Dq receptor. We did not observe any significant effect both at 1 and $20 \mu \mathrm{M}$ of CNO administration for $1 \mathrm{~h}$. Although our results ruled out any off-target effects on fEPSP time course in the Schaffer collaterals, further control experiments would be useful to rule out non-specific effects on other physiologic measures.

Behavioral studies using hM3Dq activation have employed a wide range of doses of $\mathrm{CNO}$ ranging from 0.1 to 20 mg/kg (Alexander et al., 2009; Ray et al., 2011; Mahler et al., 2014; MacLaren et al., 2016). Recent studies in rat models indicate that intraperitoneal injection of CNO (5 $\mathrm{mg} / \mathrm{kg}$ ) results in plasma concentrations of up to $2 \mu \mathrm{M}$ $\mathrm{CNO}$, which persist in the micromolar range for $90 \mathrm{~min}$ (MacLaren et al., 2016). However, a report by Gomez et al., did not find detectable CNO levels in the brain following systemic $\left[{ }^{3} \mathrm{H}\right] \mathrm{CNO}(\sim 5 \mu \mathrm{g} / \mathrm{kg})$ intraperitoneal injections in C57BL/6J mice, although the dose used was very low as compared to that standardly used for behavioral experiments (Gomez et al., 2017). It is important to consider that the metabolism and pharmacodynamics of CNO could vary across strains, species, sex, and age, and our results motivate future experiments to precisely measure $\mathrm{CNO}$ levels within distinct brain regions and their physiologic effects across distinct doses and time scales.

In conclusion, our data elucidate that treating hM3Dq DREADD activation simply as neuronal excitation, misses the nuances of regulation of various aspects of neurotransmission over time scales and across dose ranges. It is possible that different doses of CNO can have very 
different pharmacological effects including recruitment of differential downstream signaling pathways, differential internalization kinetics, and cross talk with other ionotropic and metabotropic receptors. The signaling pathways recruited by activation of GPCRs like hM3Dq are arguably distinct from those recruited during the use of optogenetic methods to activate ion channels such as $\mathrm{ChR}$. Although chemogenetic tools are invaluable in the quest for neuronal circuit/cell-specific modulation of behavior, our results motivate future experiments to carefully address the physiologic effects of hM3Dq DREADD activation as an important component during interpretation of behavioral data.

\section{References}

Alexander GM, Rogan SC, Abbas Al, Armbruster BN, Pei Y, Allen JA, Nonneman RJ, Hartmann J, Moy SS, Nicolelis MA, McNamara JO, Roth BL (2009) Remote control of neuronal activity in transgenic mice expressing evolved $G$ protein-coupled receptors. Neuron 63:27-39.

Armbruster BN, Li X, Pausch MH, Herlitze S, Roth BL (2007) Evolving the lock to fit the key to create a family of $G$ protein-coupled receptors potently activated by an inert ligand. Proc Natl Acad Sci USA 104:5163-5168.

Atasoy D, Betley JN, Su HH, Sternson SM (2012) Deconstruction of a neural circuit for hunger. Nature 488:172-177.

Augustine GJ, Santamaria F, Tanaka K (2003) Local calcium signaling in neurons. Neuron 40:331-346.

Bellone C, Lüscher C, Mameli M (2008) Mechanisms of synaptic depression triggered by metabotropic glutamate receptors. Cell Mol Life Sci 65:2913-2923.

Berridge MJ (1998) Neuronal calcium signaling. Neuron 21:13-26.

Berridge MJ (1993) Inositol trisphosphate and calcium signalling. Nature 361:315-325.

Berridge MJ (2009) Inositol trisphosphate and calcium signalling mechanisms. Biochim Biophys Acta 1793:933-940.

Billups D, Billups B, Challiss RAJ, Nahorski SR (2006) Modulation of Gq-protein-coupled inositol trisphosphate and $\mathrm{Ca} 2+$ signaling by the membrane potential. J Neurosci 26:9983-9995.

Brager DH, Johnston D (2007) Plasticity of intrinsic excitability during long-term depression is mediated through mGluR-dependent changes in I(h) in hippocampal CA1 pyramidal neurons. J Neurosci 27:13926-13937.

Britt JP, Bonci A (2013) Optogenetic interrogations of the neural circuits underlying addiction. Curr Opin Neurobiol 23:539-545.

Bröcher S, Artola A, Singer W (1992) Agonists of cholinergic and noradrenergic receptors facilitate synergistically the induction of long-term potentiation in slices of rat visual cortex. Brain Res 573:27-36.

Burgard EC, Sarvey JM (1990) Muscarinic receptor activation facilitates the induction of long-term potentiation (LTP) in the rat dentate gyrus. Neurosci Lett 116:34-39.

Caruana DA, Warburton EC, Bashir ZI (2011) Induction of activitydependent LTD requires muscarinic receptor activation in medial prefrontal cortex. J Neurosci 31:18464-18478.

Cobb SR, Davies CH (2005) Cholinergic modulation of hippocampal cells and circuits. J Physiol 562:81-88.

Das AK, Maity BK, Surendran D, Tripathy U, Maiti S (2017) Label-free ratiometric imaging of serotonin in live cells. ACS Chem Neurosci 8:2369-2373.

Davidkova G, Carroll RC (2007) Characterization of the role of microtubule-associated protein $1 \mathrm{~B}$ in metabotropic glutamate receptor-mediated endocytosis of AMPA receptors in hippocampus. J Neurosci 27:13273-13278.

Fitzjohn SM, Kingston AE, Lodge D, Collingridge GL (1999) DHPGinduced LTD in area CA1 of juvenile rat hippocampus; character- isation and sensitivity to novel mGlu receptor antagonists. Neuropharmacology 38:1577-1583.

Garner AR, Rowland DC, Hwang SY, Baumgaertel K, Roth BL, Kentros C, Mayford M (2012) Generation of a synthetic memory trace. Science 335:1513-1516.

Gladding CM, Fitzjohn SM, Molnár E (2009) Metabotropic glutamate receptor-mediated long-term depression: molecular mechanisms. Pharmacol Rev 61:395-412.

Gomez JL, Bonaventura J, Lesniak W, Mathews WB, Sysa-Shah P, Rodriguez LA, Ellis RJ, Richie CT, Harvey BK, Dannals RF, Pomper MG, Bonci A, Michaelides M (2017) Chemogenetics revealed: DREADD occupancy and activation via converted clozapine. Science 357:503-507.

Guettier JM, Gautam D, Scarselli M, Ruiz de Azua I, Li JH, Rosemond E, Ma X, Gonzalez FJ, Armbruster BN, Lu H, Roth BL, Wess J (2009) A chemical-genetic approach to study G protein regulation of beta cell function in vivo. Proc Natl Acad Sci USA 106:1919719202.

Huang CC, You JL, Wu MY, Hsu KS (2004) Rap1-induced p38 mitogen-activated protein kinase activation facilitates AMPA receptor trafficking via the GDI·Rab5 complex. J Biol Chem 279: 12286-12292.

Huber KM, Kayser MS, Bear MF (2000) Role for rapid dendritic protein synthesis in hippocampal mGluR-dependent long-term depression. Science 288:1254-1257.

Hurni N, Kolodziejczak M, Tomasello U, Badia J, Jacobshagen M, Prados J, Dayer A (2017) Transient cell-intrinsic activity regulates the migration and laminar positioning of cortical projection neurons. Cereb Cortex 27:3052-3063.

Kim CK, Adhikari A, Deisseroth K (2017) Integration of optogenetics with complementary methodologies in systems neuroscience. Nat Rev Neurosci 18:222-235.

Kong D, Tong Q, Ye C, Koda S, Fuller PM, Krashes MJ, Vong L, Ray RS, Olson DP, Lowell BB (2012) GABAergic RIP-Cre neurons in the arcuate nucleus selectively regulate energy expenditure. Cell 151: 645-657.

Kozorovitskiy Y, Saunders A, Johnson CA, Lowell BB, Sabatini BL (2012) Recurrent network activity drives striatal synaptogenesis. Nature 485:646-650.

Krashes MJ, Koda S, Ye C, Rogan SC, Adams AC, Cusher DS, Maratos-Flier E, Roth BL, Lowell BB (2011) Rapid, reversible activation of AgRP neurons drives feeding behavior in mice. J Clin Invest 121:1424-1428.

Kumar A (2010) Carbachol-induced long-term synaptic depression is enhanced during senescence at hippocampal CA3-CA1 synapses. J Neurophysiol 104:607-616.

Larkum ME, Watanabe S, Nakamura T, Lasser-Ross N, Ross WN (2003) Synaptically activated $\mathrm{Ca}^{2+}$ waves in layer $2 / 3$ and layer 5 rat neocortical pyramidal neurons. J Physiol 549:471-488.

López AJ, Kramár E, Matheos DP, White AO, Kwapis J, VogelCiernia A, Sakata K, Espinoza M, Wood MA (2016) Promoterspecific effects of DREADD modulation on hippocampal synaptic plasticity and memory formation. J Neurosci 36:3588-3599.

Lowe DG (2004) Distinctive image features from scale-invariant keypoints. Int J Comp Vis 60:91-110.

MacDonald JF, Jackson MF, Beazely MA (2007) G protein-coupled receptors control NMDARs and metaplasticity in the hippocampus. Biochim Biophys Acta 1768:941-951.

MacLaren DAA, Browne RW, Shaw JK, Krishnan Radhakrishnan S, Khare P, Espana RA, Clark SD (2016) Clozapine N-oxide administration produces behavioral effects in Long-Evans rats: implications for designing DREADD experiments. eNeuro 3.

Mahler SV, Vazey EM, Beckley JT, Keistler CR, McGlinchey EM, Kaufling J, Wilson SP, Deisseroth K, Woodward JJ, Aston-Jones G (2014) Designer receptors show role for ventral pallidum input to ventral tegmental area in cocaine seeking. Nat Neurosci 17:577585.

Mao L, Yang L, Tang Q, Samdani S, Zhang G, Wang JQ (2005) The scaffold protein Homer $1 \mathrm{~b} / \mathrm{c}$ links metabotropic glutamate receptor 
5 to extracellular signal-regulated protein kinase cascades in neurons. J Neurosci 25:2741-2752.

Mayford M, Bach ME, Huang YY, Wang L, Hawkins RD, Kandel ER (1996) Control of memory formation through regulated expression of a CaMKII transgene. Science 274:1678-1683.

Moult PR, Corrêa SAL, Collingridge GL, Fitzjohn SM, Bashir ZI (2008) Co-activation of p38 mitogen-activated protein kinase and protein tyrosine phosphatase underlies metabotropic glutamate receptordependent long-term depression. J Physiol 586:2499-2510.

Nakamura T, Nakamura K, Lasser-Ross N, Barbara JG, Sandler VM, Ross WN (2000) Inositol 1,4,5-trisphosphate (IP3)-mediated Ca2+ release evoked by metabotropic agonists and backpropagating action potentials in hippocampal CA1 pyramidal neurons. J Neurosci 20:8365-8376.

Natsume K, Kometani K (1997) $\theta$-activity-dependent and -independent muscarinic facilitation of long-term potentiation in guinea pig hippocampal slices. Neurosci Res 27:335-341.

Nichols CD, Roth BL (2009) Engineered G-protein coupled receptors are powerful tools to investigate biological processes and behaviors. Front Mol Neurosci 2:16.

Palmer MJ, Irving AJ, Seabrook GR, Jane DE, Collingridge GL (1997) The group I mGlu receptor agonist DHPG induces a novel form of LTD in the CA1 region of the hippocampus. Neuropharmacology 36:1517-1532.

Pei Y, Rogan SC, Yan F, Roth BL (2008) Engineered GPCRs as tools to modulate signal transduction. Physiology (Bethesda) 23:313321.

Peñagarikano O, Lázaro MT, Lu XH, Gordon A, Dong H, Lam HA, Peles E, Maidment NT, Murphy NP, Yang XW, Golshani P, Geschwind DH (2015) Exogenous and evoked oxytocin restores social behavior in the Cntnap2 mouse model of autism. Sci Transl Med 7:271ra8.

Ray RS, Corcoran AE, Brust RD, Kim JC, Richerson GB, Nattie E, Dymecki SM (2011) Impaired respiratory and body temperature control upon acute serotonergic neuron inhibition. Science 333:637-642.
Roth BL (2016) DREADDs for neuroscientists. Neuron 89:683-694.

Rumbaugh G, Vicini S (1999) Distinct synaptic and extrasynaptic NMDA receptors in developing cerebellar granule neurons. J Neurosci 19:10603-10610.

Rush AM, Wu J, Rowan MJ, Anwyl R (2002) Group I metabotropic glutamate receptor (mGluR)-dependent long-term depression mediated via p38 mitogen-activated protein kinase is inhibited by previous high-frequency stimulation and activation of mGluRs and protein kinase $\mathrm{C}$ in the rat dentate gyrus in vitro. $\mathrm{J}$ Neurosci 22:6121-6128.

Schoepp DD, Monn JA, Marek GJ, Aghajanian G, Moghaddam B (1999) LY354740: a systemically active mGlu2/mGlu3 receptor agonist. CNS Drug Rev 5:1-12.

Snyder EM, Philpot BD, Huber KM, Dong X, Fallon JR, Bear MF (2001) Internalization of ionotropic glutamate receptors in response to mGluR activation. Nat Neurosci 4:1079-1085.

Thomas AP, Bird GS, Hajnóczky G, Robb-Gaspers LD, Putney JW (1996) Spatial and temporal aspects of cellular calcium signaling. FASEB J 10:1505-1517.

Urban DJ, Roth BL (2015) DREADDs (designer receptors exclusively activated by designer drugs): chemogenetic tools with therapeutic utility. Annu Rev Pharmacol Toxicol 55:399-417.

Urban DJ, Zhu H, Marcinkiewcz CA, Michaelides M, Oshibuchi $\mathrm{H}$, Rhea D, Aryal DK, Farrell MS, Lowery-Gionta E, Olsen RHJ, Wetsel WC, Kash TL, Hurd YL, Tecott LH, Roth BL (2016) Elucidation of the behavioral program and neuronal network encoded by dorsal raphe serotonergic neurons. Neuropsychopharmacology 41: 1404-1415.

Volk LJ, Pfeiffer BE, Gibson JR, Huber KM (2007) Multiple Gqcoupled receptors converge on a common protein synthesisdependent long-term depression that is affected in fragile $X$ syndrome mental retardation. J Neurosci 27:11624-11634.

Xie Y, Jackson MF, Macdonald JF (2013) Optogenetics and synaptic plasticity. Acta Pharmacol Sin 34:1381-1385. 